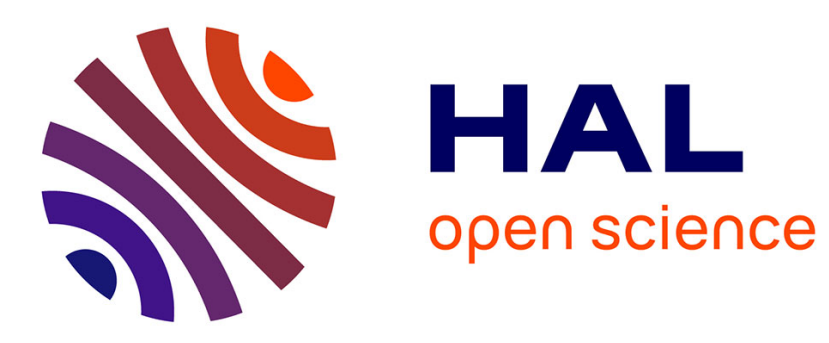

\title{
3D printed sandwich materials filled with hydrogels for extremely low heat release rate
}

\author{
Laura Geoffroy, Anne-Lise Davesne, Séverine Bellayer, Florent Blanchard, \\ Elodie Richard, Fabienne Samyn, Maude Jimenez, Serge Bourbigot
}

\section{- To cite this version:}

Laura Geoffroy, Anne-Lise Davesne, Séverine Bellayer, Florent Blanchard, Elodie Richard, et al.. 3D printed sandwich materials filled with hydrogels for extremely low heat release rate. Polymer Degradation and Stability, 2020, 179, pp.109269. 10.1016/j.polymdegradstab.2020.109269 . hal02926297

\section{HAL Id: hal-02926297 \\ https://hal.univ-lille.fr/hal-02926297}

Submitted on 31 Aug 2020

HAL is a multi-disciplinary open access archive for the deposit and dissemination of scientific research documents, whether they are published or not. The documents may come from teaching and research institutions in France or abroad, or from public or private research centers.
L'archive ouverte pluridisciplinaire HAL, est destinée au dépôt et à la diffusion de documents scientifiques de niveau recherche, publiés ou non, émanant des établissements d'enseignement et de recherche français ou étrangers, des laboratoires publics ou privés. 


\title{
3D Printed Sandwich Materials Filled with Hydrogels for Extremely Low Heat Release Rate
}

\author{
Laura GEOFFROY ${ }^{1}$, Anne-lise DAVESNE1, Séverine BELLAYER ${ }^{1}$, Florent \\ BLANCHARD ${ }^{2}$, Elodie RICHARD ${ }^{3}$, Fabienne SAMYN ${ }^{1}$, Maude JIMENEZ ${ }^{1}$, Serge \\ BOURBIGOT ${ }^{*}$
}

${ }^{1}$ Univ. Lille, CNRS, INRAE, Centrale Lille, UMR 8207 - UMET - Unité Matériaux et Transformations, F-59000 Lille, France

${ }^{2}$ Univ. Lille, CNRS, Centrale Lille, Univ. Artois, UMR 8181 - UCCS - Unité de Catalyse et Chimie du Solide, F-59000 Lille, France

${ }^{3}$ Univ. Lille, CNRS, INSERM, CHU Lille, Institut Pasteur de Lille, US 41 - UMS 2014 - PLBS, F59000 Lille, France

laura.geoffroy@univ-lille.fr (L.G.), anne-lise.davesne@univ-lille.fr (A-L. D.), severine.bellayer@univ-lille.fr (Se.B.), florent.blanchard@univ-lille.fr (F.B.), elodie.richard@univ-lille.fr (E.R.), fabienne.samyn@univ-lille.fr (F.S.), maude.jimenez@univ-lille.fr (M.J.)

*corresponding author: serge.bourbigot@ univ-lille.fr (S.B.); Phone: +33 (0)3 20434888

Keywords: Additive manufacturing, Design, Hydrogel, Sandwich multi-materials, Flame retardancy

\begin{abstract}
:
Additive manufacturing is a powerful tool to design materials with original properties. An innovative design of poly (Ethylene Vinyl Acetate) (EVA) containing $30 \mathrm{wt} .-\%$ of Aluminum TriHydroxide (ATH) was reported in a previous paper and liquids (water or potassium carbonate aqueous solution) were incorporated in the $3 \mathrm{D}$ printed structure. These multi-materials showing interesting properties, but stability, control and processing of these liquid-containing systems were an issue due to porosity of the polymeric matrix. To overcome this issue, the use of hydrogels is considered in this study: being either solid or highly viscous, hydrogels can retain water in the design, despite the high porosity of the EVA/ATH matrix. In this paper, the liquid phase was substituted by flame retardant hydrogels (based on agar, alginate or poly (vinyl alcohol) - PVA), containing in particular vermiculite platelets and for the hydrogel based on alginate, $\mathrm{K}_{2} \mathrm{CO}_{3}$ as flame retardant fillers. Excellent behavior under a $50 \mathrm{~kW} / \mathrm{m}^{2}$ heat flux during a cone calorimeter test was obtained, with fast extinguishment of the flame and a low peak of Heat Release Rate (pHRR) and Total Heat Release (THR). The physical barrier formed by vermiculite platelets during the test, as well as the condensed phase mechanism of $\mathrm{K}_{2} \mathrm{CO}_{3}$ were found to be responsible for these excellent results, as found by confocal microscopy observations, electron probe micro analysis and X-Ray diffraction experiments.
\end{abstract}




\section{Graphical abstract:}

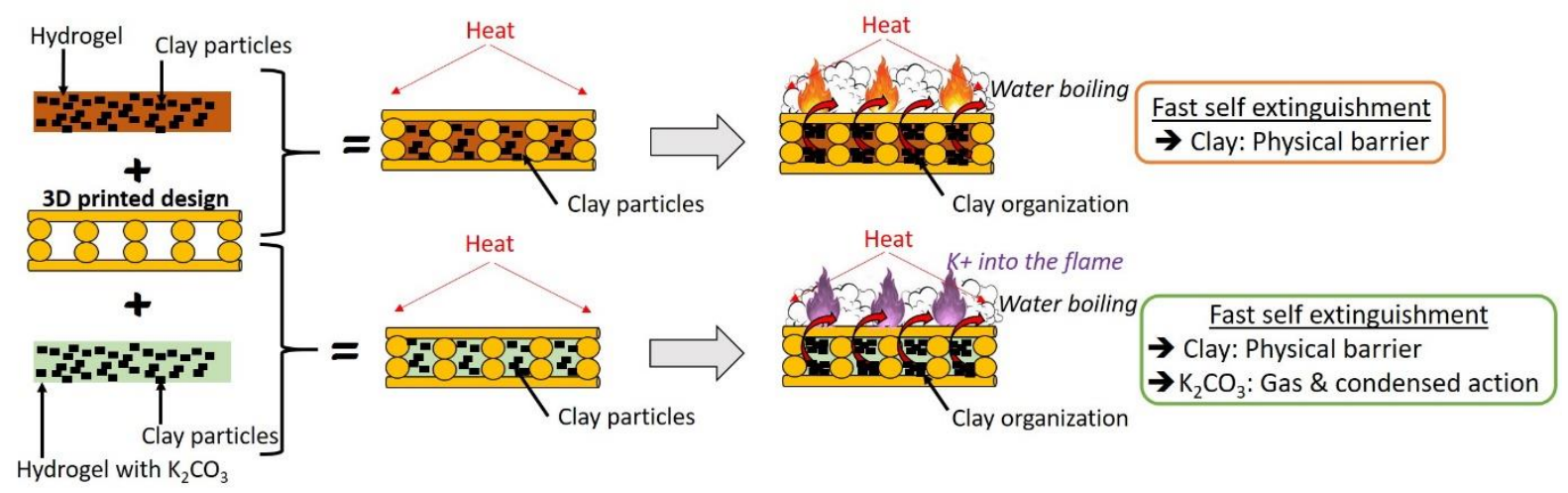

\section{Introduction}

The light weight and functional properties of polymers have made their use constant and in perpetual growth, for example in building and transportation fields. Unfortunately, the high flammability of most polymers threatens human lives and infrastructures, and fire retardant solutions are therefore an absolute need. Conventional solutions involve adding fire retardant fillers in the bulk of the polymeric materials. On the other hand, additive manufacturing, or 3D-printing, is a tool that has gathered a lot of interest. The capability to create original designs and the possibility to obtain unique properties or to optimize them by adjusting the morphology of the material, has open a wide range of prospects for the creation of innovative materials [1], [2].

Therefore, polymer additive manufacturing is a great opportunity to design materials with improved flame resistance and more particularly flame retardancy, by playing on the design rather than on the chemistry. However, most current works focus on adapting the process to print polymers containing fire-retardant fillers for fast prototyping and proof of concept, rather than investigating new designs. Guo et al, for example, have printed a fire-retardant formulation of PLA containing Melamine Polyphosphate (MPP), and found that they could maintain its fire performance through 3D-printing [3]. Koo et al. focused on printing fire-retardant polyamides and polymer composites [4-6].

In a previous paper, it was reported that a fire-retarded formulation of an ethylene-vinyl acetate (hereafter call EVA) copolymer containing 30\% weight amount of Aluminum TriHydroxide (ATH) can be processed to create flame-retardant materials by 3D-printing [7]. Following this research, an original design was elaborated and innovative sandwich multimaterials filled with a liquid phase were prepared. The design consists of a core of EVA-ATH, with square-shaped empty cells so that $30 \%$ of the resulting plate is composed of EVA-ATH in the end. This core is sandwiched between two full skins of the same polymer. The cells were then filled with a saturated solution of $\mathrm{K}_{2} \mathrm{CO}_{3}$, which was selected as it is a well-known additive used in commercial fire extinguishing systems [8-11] as well as in the fire vase concept developed by Samsung (Seoul, South Korea) [12]. The final material was tested by mass loss 
cone calorimetry and was found to extinguish immediately after ignition thanks to the release of $\mathrm{CO}_{2}$, $\mathrm{H}_{2} \mathrm{O}, \mathrm{K}$ and $\mathrm{KOH}$ quenching the flame, resulting in very low heat release rate. The issue was that the amount of liquid added that was not easily controlled because of the porosity of the system causing unavoidable leaks [13].

In this paper, the combination of 3D-printing process to produce innovative fire retardant materials is further pursued, by filling the core of the previously described EVA-ATH sandwich multimaterial with fire retardant hydrogels. First, from an engineering point of view, this would allow to overcome this issue of leakage. Concurrently, the aim is also to take advantage of both 3D-printing and the hydrogels properties to manage and seal a high amount of water to add additional fire retardant properties to a material, by retarding ignition and quenching the flame. Hydrogels are indeed composed of a polymer network cross-linked in water. The resulting material can be either solid or highly viscous depending on the network, the fabrication process, and the cross-linking system, with water being the major component. Some hydrogels are already used for protection against fire, mainly as active components in extinguishing systems [14], [15]. Widusha et al [16] suggested the idea of using them as fire resistant solution in fabric laminates, since their high water content could limit the temperature rise for a certain time, until water evaporates and dilutes the reactive species in the flame to blow it out. Despite their high interest, they have only been used as active fire protective solution [17], [18], and never as potential fire retardant material, which is here made possible by the use of a 3D-printed hollow polymer core acting as a container for the hydrogel. In this work, three polymers which easily form hydrogels in water through different gelation processes were investigated: alginate, agar and poly (vinyl alcohol) (PVA). The different gelation processes, could provide insights on if and how this has an influence on the fire behavior of the final material. Fire retardant additives were introduced in the hydrogel, first by making hydrogel composite filled with vermiculite, a clay. Vermiculite was already tested as a fire retardant filler, usually included in polymer formulation [19], [20] or in thin coatings, such as in layer-by-layer systems [21]. It is believed to act as a char promoting agent and as physical barrier against heat and mass transfer [22]. In a second step, the possibility of including $\mathrm{K}_{2} \mathrm{CO}_{3}$ in the hydrogel formulation was examined to take advantage of its action against fire [13]. All samples were tested by mass loss cone calorimetry at an external heat flux of $50 \mathrm{~kW} / \mathrm{m}^{2}$. Full characterizations by confocal microscope, Electron Probe Micro Analysis (EPMA), and XRD before and after fire tests were also carried out, to investigate the fire protection mechanism.

\section{Materials and methods}

\section{Materials}

The 3D printed designs were made using EVA (Evatane 28-05), a copolymer of ethylene and vinyl acetate (molar mass: $114.142 \mathrm{~g} / \mathrm{mol}$, Melt index between $5-8 \mathrm{~g} / 10 \mathrm{~min}$ (at $190^{\circ} \mathrm{C}, 2.16 \mathrm{~kg}$ ) [23]), supplied by Arkema (Colombes, France) as polymeric matrix and ATH (Apyral 40CD, $\mathrm{D}_{50}$ of $1.5 \mu \mathrm{m}$ ) 
and purchased from Nabaltec (Schwandorf, Germany) as a flame retardant additive. ATH decomposes according to an endothermic reaction $\left(2 \mathrm{Al}(\mathrm{OH})_{3} \rightarrow \mathrm{Al}_{2} \mathrm{O}_{3}+3 \mathrm{H}_{2} \mathrm{O}\right)$ [24] with formation of alumina acting as a protective ceramic and evolving water, acting as diluent of the flame.

Hydrogels were prepared using the hereafter presented chemicals. Sodium alginate (molar mass: 216.12 g/mol, viscosity: $5-40 \mathrm{cps}$ for $1 \mathrm{wt} .-\%$ water at $25^{\circ} \mathrm{C}$ [25]), PVA (molar mass: $86.09 \mathrm{~g} / \mathrm{mol}$, viscosity: $24-32$ cps for 4 wt.- $\%$ water at $20^{\circ} \mathrm{C}$ [26]), calcium chloride $\left(\mathrm{CaCl}_{2}\right)$, citric acid and potassium carbonate $\left(\mathrm{K}_{2} \mathrm{CO}_{3}, 98 \%\right.$ purity) were supplied by Sigma Aldrich (St Louis, Missouri, United States). Agar (molar mass: $336.33 \mathrm{~g} / \mathrm{mol}$, viscosity: $10-100 \mathrm{cps}$ for 1.5 wt.-\% water at $60^{\circ} \mathrm{C}$ [27]) from Mc Cormick (Baltimore, Maryland, United States), was used as well as borax from Borax Europe Ltd (Kolding, Denmark) and a solution of dispersed vermiculite (VMT) (Microlite 963, 7.8 wt.-\% in water, Specialty Vermiculite Corp., Enoree, South California, United States).

\section{Polymer matrix processing}

A formulation of EVA containing 30 wt.- $\%$ of ATH additives (EVA/ATH (30 wt.- $\%$ )) was prepared using a twin-screw extruder (Haake Rheomex OS PTW16, Thermo Scientific (Waltham, Massachusetts, United States of America)) (Figure 1). The extrusion speed reached $100 \mathrm{rpm}$ during the extrusion process. This twin-screw extruder was composed of ten zones with set temperatures: $150^{\circ} \mathrm{C}, 160^{\circ} \mathrm{C}$, $160^{\circ} \mathrm{C}, 160^{\circ} \mathrm{C}, 170^{\circ} \mathrm{C}, 170^{\circ} \mathrm{C}, 170^{\circ} \mathrm{C}, 160^{\circ} \mathrm{C}, 160^{\circ} \mathrm{C} 150^{\circ} \mathrm{C}$, from the polymer feeding to the material die, respectively. ATH was added thanks to a gravimetric feeder in zone four (at $\left.160^{\circ} \mathrm{C}\right)$. EVA/ATH $(30$ wt.-\%) material was cooled down in air and pelletized (pelletizer Thermo Scientific (Waltham, Massachusetts, United States of America)).

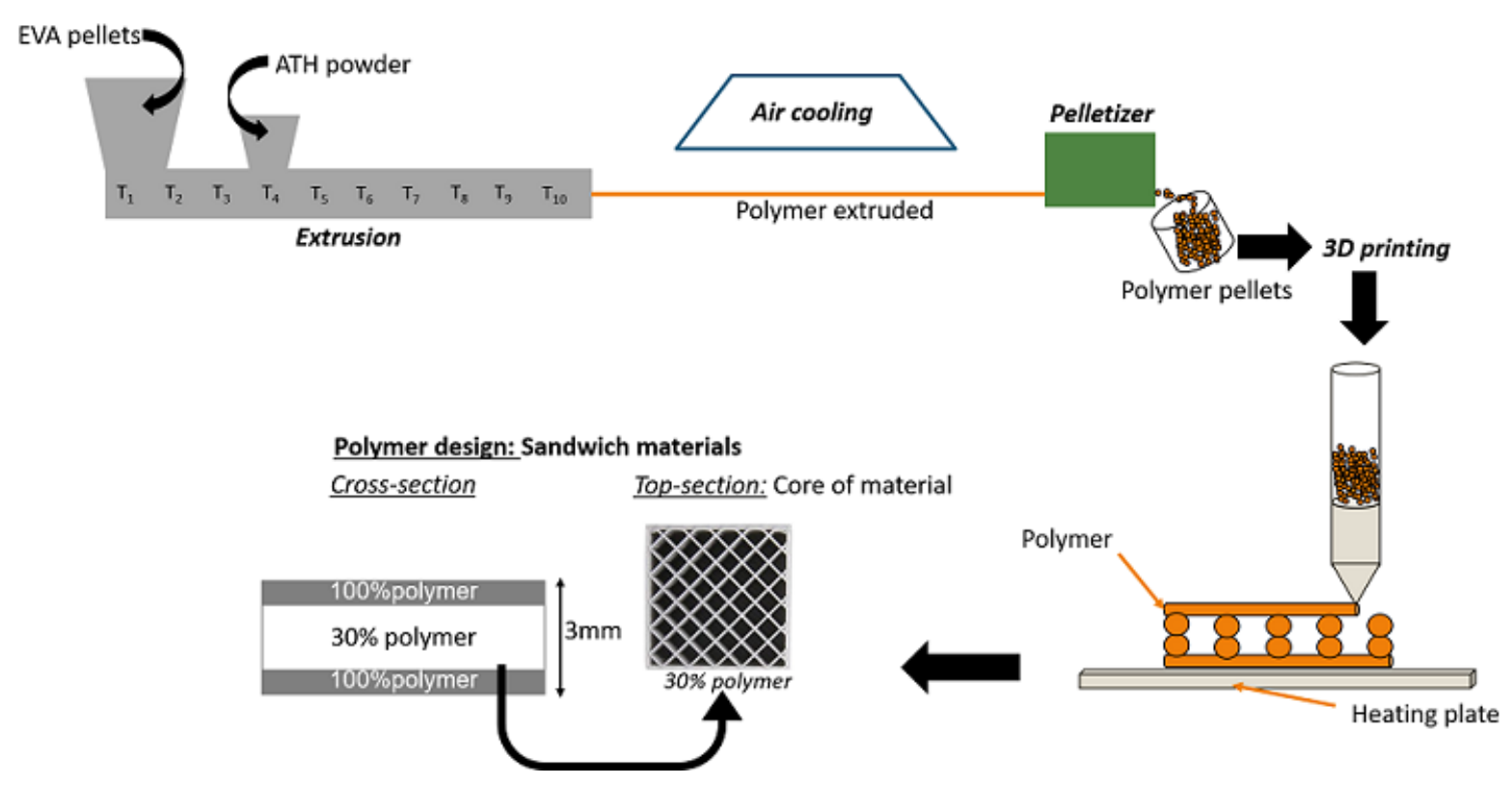




\section{Printed samples}

EVA/ATH (30 wt.\%) pellets were then used to print 50x50x3 $\mathrm{mm}^{3}$ EVA/ATH (30 wt.-\%) polymer plates, according to a computer pattern using a Pollen (Ivry-sur-Seine, France) 3D printer, fully described elsewhere [7]. EVA/ATH (30 wt.-\%) polymer pellets were incorporated on a feeder, then went through an extruder with a thermal gradient from $65^{\circ} \mathrm{C}$ to $130^{\circ} \mathrm{C}$ in the middle until $225^{\circ} \mathrm{C}$ at the output of extruder. To elaborate the final 3D object, a fused polymer filament is deposited layer by layer on a heated plate $\left(65^{\circ} \mathrm{C}\right.$ ), which moves at $20 \mathrm{~mm} / \mathrm{s}$ (Figure 1). The nozzle diameter was equal at $0.8 \mathrm{~mm}$, and the layer height correspond to $0.3 \mathrm{~mm}$.

Based on a previous paper [13], a sandwich design was conceived. It consists of two skins made of $100 \%$ filled layers of EVA-ATH, and a partially-filled core (30\% of polymer), as illustrated in Figure 1. To be able to fill the empty cells of the core created by the design and thus elaborate the sandwich multi-materials with various phases, the top skin was printed separately from the bottom skin and core.

\section{Hydrogel and sandwich multi-materials elaboration process}

\subsection{Reference hydrogels}

Hydrogel A was prepared by dissolving 3 wt.- $\%$ of sodium alginate in hot distilled water $\left(\right.$ at $\left.70^{\circ} \mathrm{C}\right)$, under magnetic stirring. A controlled mass of alginate solution (around $2.7 \mathrm{~g}$ ) is then poured in the core polymer design and directly plunged overnight into a water based gelation bath containing 2 wt.- $\%$ of $\mathrm{CaCl}_{2}$ and $0.5 \mathrm{M}$ of citric acid monohydrate (Figure $2 \mathrm{a}$ ). Physical cross-linking occurs to ensure the formation of the hydrogel phase (Figure 2 a). It is noteworthy that citric acid was used in gelation bath in addition to $\mathrm{CaCl}_{2}$ to form alginate-gel to avoid the retraction of gel [28].

Hydrogel B is formed by dissolving $0.7 \mathrm{wt} .-\%$ of agar in boiling water $\left(\right.$ at $\left.100^{\circ} \mathrm{C}\right)$ under magnetic stirring (Figure $2 \mathrm{c}$ ). The hot agar solution is then poured (with a controlled mass around $2.7 \mathrm{~g}$ ) in the core, and leaved to cool down at room temperature. The gelation process occurs when the agar solution reaches room temperature.

For hydrogel C, 3 wt.-\% PVA is dissolved and stirred in hot distilled water (at $75^{\circ} \mathrm{C}$ ). Then, crosslinking in hydrogel C occurs by adding $0.6 \mathrm{wt} .-\%$ of borax in the stirred solution of PVA (Figure $2 \mathrm{~d}$ ) [29]. The stirring is maintained until the solution cooled-down at room temperature and the gel is formed. Afterwards, the gel is incorporated in the empty cells of the core directly, with a controlled mass around of $2.7 \mathrm{~g}$. Due to the constant stirring during the gel formation to ensure its homogeneity, hydrogel $\mathrm{C}$ has to be applied in the empty cells of the core polymer design after gelation. However, thanks to its soft texture, hydrogel $\mathrm{C}$ is easily applied (Figure $2 \mathrm{~d}$ ). 


\subsection{Hydrogels containing vermiculite and vermiculite $/ \mathrm{K}_{2} \mathrm{CO}_{3}$}

Hydrogels containing vermiculite or vermiculite and $\mathrm{K}_{2} \mathrm{CO}_{3}$ were then prepared in order to improve the fire retardant performances of the hydrogels A, B, C.

Three new composite hydrogels containing vermiculite named A+VMT, B+VMT and C+VMT were elaborated. A commercial solution of dispersed vermiculite at $7.8 \mathrm{wt.}$ - $\%$ in water was diluted to $7 \mathrm{wt}$ $\%$ using distilled water and heated to the appropriate temperature $\left(70^{\circ} \mathrm{C}\right.$ for $\mathrm{A}+\mathrm{VMT}, 100^{\circ} \mathrm{C}$ for $\mathrm{B}+\mathrm{VMT}$ and $75^{\circ} \mathrm{C}$ for $\mathrm{C}+\mathrm{VMT}$ ). Then the gels $\mathrm{A}+\mathrm{VMT}, \mathrm{B}+\mathrm{VMT}$ and $\mathrm{C}+\mathrm{VMT}$ were prepared by respectively adding sodium alginate, agar and PVA directly into the solution, then pouring it in the empty cells of the core polymer design before (or after for $\mathrm{C}+\mathrm{VMT}$ ) carrying the cross-linking step as previously mentioned (Figure $2 \mathrm{a}, \mathrm{c}, \mathrm{d}$ ).

Finally, the incorporation of $\mathrm{K}_{2} \mathrm{CO}_{3}$ in the previously prepared gels containing VMT was not straightforward. Indeed, its addition in B+VMT and $\mathrm{C}+\mathrm{VMT}$ causes VMT particles to agglomerate and thus prevent the gel formation whereas it disrupts the crosslinking process of $\mathrm{A}+\mathrm{VMT}$ as it reacted with $\mathrm{CaCl}_{2}$ and the citric acid to yield $\mathrm{CaCO}_{3}$ and $\mathrm{CO}_{2}$ (Figure $2 \mathrm{~b}$ ). Likewise, alginate and $\mathrm{K}_{2} \mathrm{CO}_{3}$, agar with $\mathrm{K}_{2} \mathrm{CO}_{3}$ or PVA/Borax with $\mathrm{K}_{2} \mathrm{CO}_{3}$ alone (without VMT) did not form a gel. Nevertheless, a gel containing alginate, VMT and $\mathrm{K}_{2} \mathrm{CO}_{3}$ (hereafter called $\mathrm{A}+\mathrm{VMT}+\mathrm{K}_{2} \mathrm{CO}_{3}$ ) was prepared with a modified gelation process. Based on a previous paper [13], $0.2 \mathrm{~g} / 10 \mathrm{ml}$ of $\mathrm{K}_{2} \mathrm{CO}_{3}$ was added in a solution containing $3 \mathrm{wt} .-\%$ of alginate and $7 \mathrm{wt} .-\%$ VMT (preparation previously described). The solution was then cooled down in a refrigerator for $48 \mathrm{~h} \mathrm{[30].} \mathrm{Then,} \mathrm{the} \mathrm{hydrogel} \mathrm{is} \mathrm{taken} \mathrm{out} \mathrm{of} \mathrm{the} \mathrm{fridge} \mathrm{and}$ deposited in the empty cells of the core polymer design, with a controlled mass around $2.7 \mathrm{~g}$ (Figure 2 b). 


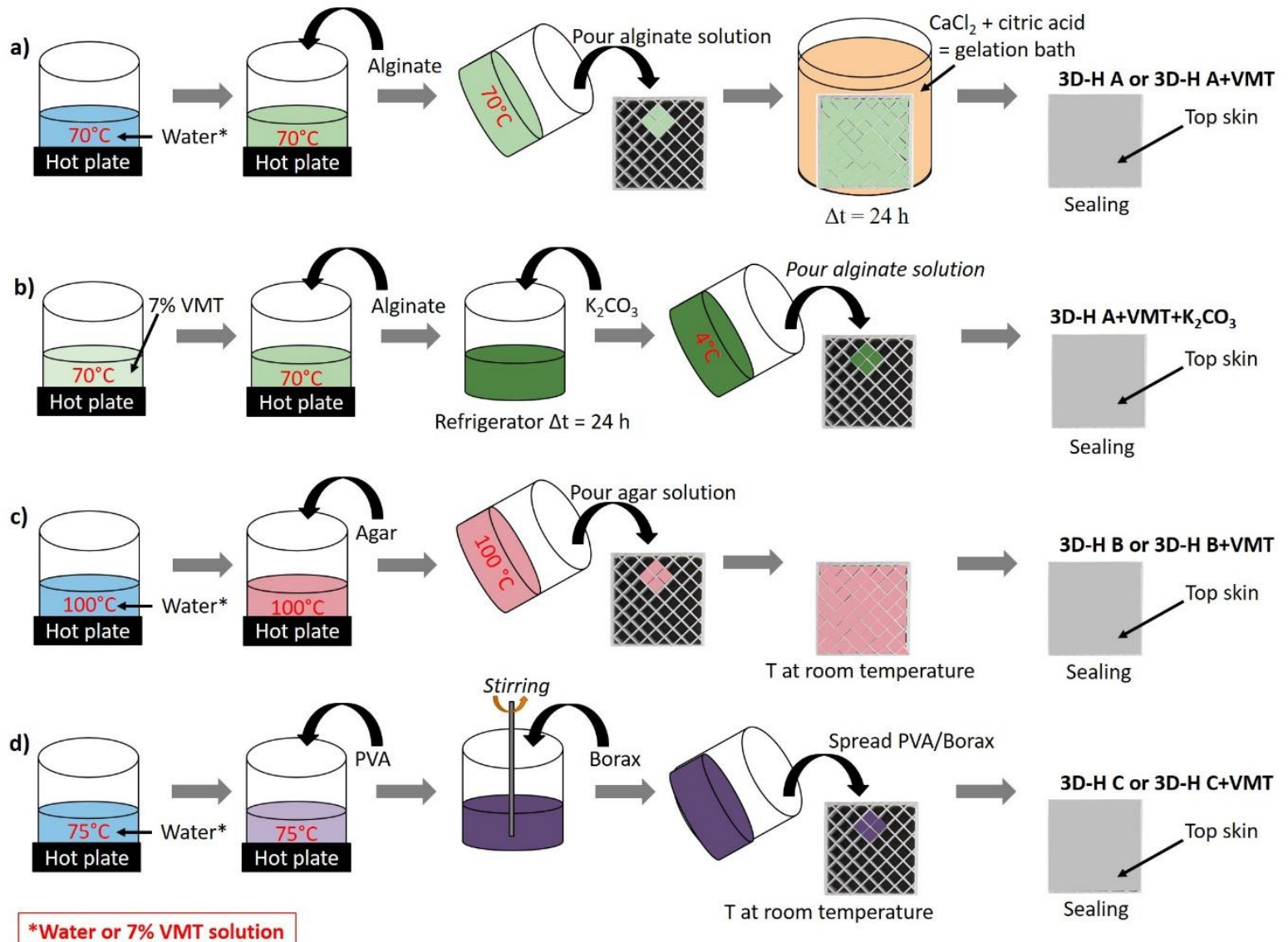

Figure 2. Hydrogel sandwich multi-materials elaboration (a) $3 D-H A$ or $\left.3 D-H A+V M T, b) 3 D-H A+V M T+K_{2} C O_{3}, c\right) 3 D-H$ B or $3 D-H B+V M T, d) 3 D-H$ C or $3 D-H C+V M T)$.

Afterwards, the design is sealed by fusing the edges of the polymer top skin to the polymer plate at $200^{\circ} \mathrm{C}$, thereby forming the final hydrogel sandwich multi-material. Seven samples were therefore prepared, their name and composition are gathered in Table 1.

To evaluate the efficiency of using hydrogel, instead of air or liquid phase, two other samples were prepared to facilitate the comparison: 3D-air, and $3 \mathrm{D}-\mathrm{K}_{2} \mathrm{CO}_{3}$ sat-liquid, where the empty cells in the core created by the design are left empty or filled in with a saturated solution of potassium carbonate, respectively.

Table 1. Name and description of samples prepared

\begin{tabular}{|c|c|c|c|c|c|}
\hline \multicolumn{2}{|c|}{ Name of the samples } & \multicolumn{2}{|c|}{ 3D printed polymer part } & \multicolumn{2}{|c|}{ Phase incorporated in core } \\
\hline & & Composition & Weight ratio & Composition & Weight ratio \\
\hline 1 & 3D-H A & \multirow{4}{*}{$\begin{array}{c}\text { EVA/ATH (30 } \\
\text { wt.- } \%)\end{array}$} & $0.67 \pm 0.01$ & Hydrogel: Alginate & $0.33 \pm 0.01$ \\
\hline 2 & 3D-H A+VMT & & $0.70 \pm 0.02$ & $\begin{array}{c}\text { Hydrogel: Alginate }+ \\
\text { VMT }\end{array}$ & $0.30 \pm 0.02$ \\
\hline 3 & $\begin{array}{c}3 \mathrm{D}-\mathrm{H} \\
\mathrm{A}+\mathrm{VMT}+\mathrm{K}_{2} \mathrm{CO}_{3}\end{array}$ & & $0.72 \pm 0.01$ & $\begin{array}{c}\text { Hydrogel: Alginate }+ \\
\text { VMT }+\mathrm{K}_{2} \mathrm{CO}_{3}\end{array}$ & $0.28 \pm 0.01$ \\
\hline 4 & 3D- H B & & $0.75 \pm 0.01$ & Hydrogel: Agar & $0.25 \pm 0.01$ \\
\hline
\end{tabular}




\begin{tabular}{|c|c|c|c|c|}
\hline 5 & 3D-H B+VMT & $0.73 \pm 0.02$ & Hydrogel: Agar + VMT & $0.27 \pm 0.02$ \\
\hline 6 & 3D-H C & $0.73 \pm 0.03$ & Hydrogel: PVA/Borax & $0.27 \pm 0.03$ \\
\hline 7 & 3D-H C+VMT & $0.74 \pm 0.01$ & $\begin{array}{c}\text { Hydrogel: PVA/Borax + } \\
\text { VMT }\end{array}$ & $0.26 \pm 0.01$ \\
\hline 8 ref & 3D-air & 1 & Air & 0 \\
\hline 9 ref & $3 \mathrm{D}-\mathrm{K}_{2} \mathrm{CO}_{3}$ sat--liquid & $0.72 \pm 0.02$ & $\begin{array}{l}\text { Liquid: Saturated } \\
\text { solution of } \mathrm{K}_{2} \mathrm{CO}_{3}\end{array}$ & $0.28 \pm 0.02$ \\
\hline
\end{tabular}

\section{Fire testing: Mass Loss Cone Calorimeter}

Heat release rate (HRR) was measured as function of time using Mass Loss Cone Calorimeter (MLCC, Fire testing technology (FTT), West Sussex, UK), according to standards ISO 13927 or ASTM E906. In such test, a conical radiant heater equivalent to the one used in oxygen consumption cone calorimetry (ASTM E-1354-90) is used. The main differences between these tests is that MLCC quantify the heat released thanks to temperature measurements made by a thermopile located on the top of the chimney, instead of measuring the oxygen consumption. The 50x50x3 $\mathrm{mm}^{3}$ samples, placed in a horizontal orientation on a load cell distant from $35 \mathrm{~mm}$ from the cone heater, were exposed to a $50 \mathrm{~kW} / \mathrm{m}^{2}$ external radiative heat flux, which corresponds to the late stage of a developing fire scenario [31]. During the heat exposure, HRR was recorded as a function of time via a data acquisition system (MLC Calc software, Radcal, Monrovia, California, United States of America). Three main parameters were determined from this curve (HRR versus time), and compared between samples: the peak of Heat Release Rate (pHRR), the Total of Heat Release (THR), and the Time To Ignition (TTI). Each prepared sample was done in triplicate, to ensure repeatability within the error margins of $\pm 10 \%$ for pHRR and THR and $\pm 15 \%$ for TTI. The average values were chosen for the comparison between samples afterward. In the middle of the backside of the polymer plate, the temperature was measured during the heat exposure. A K-type thermocouple (TC SA, Dardilly, France) was used, and fixed in a calsil plate to ensure its steadiness during the test. A graphtec 34970A data logger (Keysight Technologies, Santa Rosa, CA, USA) was used to record all data.

\section{Characterizations}

\subsection{Optical characterizations}

\subsubsection{Optical microscopy:}

Residues obtained after MLCC tests were cut using a blade, and the cross-sections were observed using a VHX-1000 HDR optical microscope (High Dynamic Range, Keyence, Osaka, Japan). 


\subsubsection{Confocal microscopy:}

The dispersion of VMT particles in hydrogel phase before MLCC tests was observed using an inverted confocal microscope (ZEISS LSM 780, Carl Zeiss MicroImaging GmbH, Jena, Germany). Fluorescence was obtained by using fluorescein (Sigma Aldrich, St Louis, Missouri, United States). When hydrogels containing VMT (H A+VMT, H B+VMT, H C+VMT) were prepared (as described in section 4. Hydrogel and sandwich multi-materials elaboration process), a $10^{-5} \mathrm{~mol} / \mathrm{L}$ solution of fluorescein was used instead of pure distilled water. Then, a drop of each hydrogel formed containing fluorescein was deposed on a thin glass slide for observation. It is noteworthy that the fluorescein loses its fluorescence properties in acidic environment (low $\mathrm{pH}$ reduces the luminescence intensity because of the existence of different protolytic reactions in the excited state due to the presence of carboxyl group, which thus influence the fluorescence) [32]. However, to form hydrogel A+VMT, a gelation bath composed of $\mathrm{CaCl}_{2}$ and acid citric is needed. The VMT dispersion observation for this hydrogel is thus not possible. For this reason, only for this hydrogel, VMT dispersion observation is done in liquid phase. The fluorescent aqueous probe was excited at $488 \mathrm{~nm}$ and emitted light was observed in the range 493 - $624 \mathrm{~nm}$. In these experiments, water appear in green due to fluorescein coloration, whereas VMT particles, not colored with fluorescein, appear in black. Observations were done using an immersion oil objective 40x, with numerical aperture of 1.3. Z stack were acquired on each sample. Finally, ImageJ software was used for image processing. Among $\mathrm{Z}$ stack pictures acquired, a representative image of sample was chosen (Figure 3).

\subsubsection{Scanning Electron Microscopy \& Electron Probe Micro-Analysis:}

Scanning Electron Microscopy (SEM) observations and X-ray mappings of the cross-section of the residues obtained after MLCC tests were carried out to analyze their aspect and figure out the elemental repartition and dispersion, respectively. To perform these observations and mappings, residues were initially embedded into an epoxy resin. After $48 \mathrm{~h}$ of curing at room temperature, samples were polished (up to $0.25 \mu \mathrm{m}$ ) using silicon carbide disks (ESCIL, Chassieu, France), followed by a carbon coating with a Bal-Tec SCD005 sputter coater (Bal-Tec, Los Angeles, California, United States). On one hand, SEM observations were performed on the residue, using a JEOL JSM 7800F LV (JEOL ltd, Tokyo, Japan) at $6.0 \mathrm{kV}$ and $121.2 \mu \mathrm{A}$. On the other hand, cross-section X-ray mappings were carried out at 15 KV, 40 nA using a Camera SX100 electron probe microanalyser (Electron Probe Micro-Analysis: EPMA) (Cameca, Gennevilliers, France). On the mappings, a color-coded legend characterizes the concentration of the element (black color: absence of the element to red color: highest concentration).

Moreover, for mappings: (1) a PC2 (a multilayer of Ni/C), was used to detect $\mathrm{K} \alpha$ of $\mathrm{C}$, (2) a Thallium Acid Phtalate (TAP) crystal was used to detect Al and Mg, (3) a Pentaerythritol (PET) crystal was used to detect $\mathrm{K}$ and (4) a Lithium Fluoride (LIF) crystal was used to detect Fe.

$\mathrm{Fe}$ and $\mathrm{Mg}$ elements were identified due to their presence in vermiculite, and thus allowed observing the vermiculite orientation. $\mathrm{K}$ and $\mathrm{Al}$ elements were chosen as characteristics elements of $\mathrm{K}_{2} \mathrm{CO}_{3}$ and $\mathrm{ATH}$ 
in EVA/ATH (30 wt.-\%), respectively. It is noteworthy that $\mathrm{K}$ and $\mathrm{Al}$ elements are also present in vermiculite particles. Nevertheless, $\mathrm{K}$ and $\mathrm{Al}$ concentration in vermiculite is lower than in $\mathrm{K}_{2} \mathrm{CO}_{3}$ and EVA/ATH (30 wt.-\%), respectively. Therefore, a distinction between these phases is easily done.

\subsection{X-ray diffraction}

Both Room-Temperature (RT-XRD) and High Temperature X-ray Diffraction (HT-XRD) experiments were done using a SmartLab@ Rigaku diffractometer (Rigaku, Tokyo, Japan) equipped with a $9 \mathrm{~kW}$

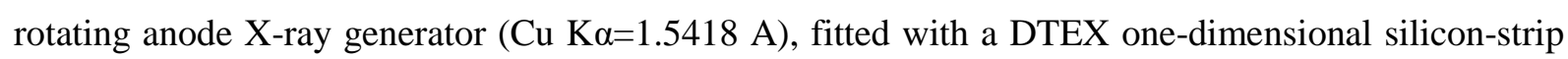
detector, in Bragg-Brentano reflection geometry. For RT, the $\theta-2 \theta$ scans were performed in the range $5^{\circ}-75^{\circ}$, with a step size of $0.03^{\circ}$ and a speed of $2^{\circ} / \mathrm{min}$, while for HT-XRD, patterns were recorded in the range $4^{\circ}-65^{\circ}$, with a step size of $0.01^{\circ}$ and a speed of $4 \% \mathrm{~min}$. The experiment was conducted under a static air atmosphere in an Anton Paar DHS1100 heating attachment, with a temperature range 25 $1000^{\circ} \mathrm{C}$, using, on heating, $25^{\circ} \mathrm{C}$ plateau (heating rate $5^{\circ} \mathrm{C} / \mathrm{min}$ between each plateau) and $50^{\circ} \mathrm{C}$ plateau at cooling. Scans were recorded after a one-minute temperature stabilization plateau.

\section{Results and discussion}

\section{Characterizations before fire test}

Mass, thickness and liquid or hydrogel amount of each system are gathered in Table 2. All hydrogel sandwich multi-materials have almost the same global mass $(9.3 \mathrm{~g} \pm 0.7 \mathrm{~g})$ and thickness $(3 \mathrm{~mm} \pm 0.1$ $\mathrm{mm}$ ). The hydrogel mass incorporated in the empty cells of the core created by the polymer design is almost very close for all systems and is equal in average to $2.6 \mathrm{~g} \pm 0.3 \mathrm{~g}$. It is noteworthy that $\mathrm{K}_{2} \mathrm{CO}_{3}$ is only incorporated in hydrogel A+VMT using a "cold way" process to obtain a gel (as previously described in the experimental part), because the formation of a hydrogel in presence of $\mathrm{K}_{2} \mathrm{CO}_{3}$ is not possible with hydrogel $\mathrm{B}$ and $\mathrm{C}$. It is assumed that due to the basic $\mathrm{pH}$ of $\mathrm{K}_{2} \mathrm{CO}_{3}$ in water, the formation of gel is very difficult and not achievable in certain case.

Table 2. Composition of sandwich multi-materials.

\begin{tabular}{cccc}
\hline Polymer matrix & Mass (g) & Thickness (mm) & Liquid / hydrogel amount (g) \\
\hline 3D-air & $5.82 \pm 0.03$ & $3 \pm 0$ & $/$ \\
\hline 3D-K2 $\mathrm{CO}_{3 \text { sat-liquid }}$ & $9.4 \pm 0.2$ & $3 \pm 0.2$ & $2.6 \pm 0.2$ \\
\hline 3D-H A & $9.40 \pm 0.03$ & $3.1 \pm 0.1$ & $3.1 \pm 0.1$ \\
\hline 3D-H A+VMT & $9.5 \pm 0.3$ & $3 \pm 0.2$ & $2.8 \pm 0.1$ \\
\hline 3D-H A+VMT+K2 $\mathrm{CO}_{3}$ & $9.9 \pm 0.1$ & $3 \pm 0.2$ & $2.8 \pm 0.2$ \\
\hline 3D-H B & $9.5 \pm 0.2$ & $3 \pm 0.2$ & $2.33 \pm 0.04$ \\
\hline 3D-H B+VMT & $9.2 \pm 0.2$ & $3 \pm 0.2$ & $2.5 \pm 0.2$ \\
\hline
\end{tabular}




\begin{tabular}{clll}
\hline 3D-H C & $8.6 \pm 0.6$ & $3 \pm 0.1$ & $2.3 \pm 0.1$ \\
\hline 3D-H C+VMT & $9.0 \pm 0.4$ & $3 \pm 0.2$ & $2.3 \pm 0.2$ \\
\hline
\end{tabular}

For VMT-containing systems, the dispersion of VMT particles in hydrogel was observed by confocal microscopy (Figure 3). In the case of hydrogel A+VMT (Figure 3 a), the gelation involving the use of an acidic bath. As it was previously explained in experimental part (confocal microscope section), the fluorescent agent loses its fluorescence properties in acidic environment [32]. Therefore, the fluorescence is lost during the hydrogel A+VMT formation preventing its observation. It is thus noteworthy that VMT dispersion observation was done on the liquid dispersion of VMT and alginate before gelation. However, for this kind of hydrogel the gelation starts immediately when the hydrogel is immerged in gelation bath. It is thus reasonable to assume that VMT dispersion in liquid and hydrogel phases is quite similar. Figure 3 a highlights that VMT particles (in black) are well dispersed in liquid phase, without preferential orientation (isotropic distribution of VMT). In hydrogel A+VMT $+\mathrm{K}_{2} \mathrm{CO}_{3}$, VMT particles show similar dispersion as in hydrogel A+VMT (Figure $3 \mathrm{~b}$ ). VMT particles have no preferential orientation, and are well dispersed. The presence of $\mathrm{K}_{2} \mathrm{CO}_{3}$ seems to have no influence on the VMT dispersion.

Regarding hydrogel $\mathrm{B}+\mathrm{VMT}$, VMT particles are oriented in preferential directions as illustrated in Figure $3 \mathrm{c}$ (anisotropic distribution of VMT). After gelation, the structure is freezed, and therefore any organization of the VMT particles wouldn't be possible if there wasn't a primary organization of VMT in the polymer/clay mixture [33], [34]. Evidence of such local ordering in dilute clay suspension was observed for example by Poiron et al [35]. Therefore, the observed preferential orientation happens before gelation and can be explained by the slow gelation process. For reminder, hydrogel B+VMT is formed when the hot solution of B+VMT is cooled down at room temperature. Therefore, during the cooling, and thanks to the low viscosity of the VMT/agar hot solution, VMT particles have enough time to organize and have an anisotropic distribution before it is frozen by the increase of the viscosity as the gel forms.

In the case of hydrogel C+VMT, some VMT particles are oriented, while others form stacks (Figure 3 d). It is noteworthy that as the PVA/VMT dispersion is stirred, it is possible that under the shear constraints anisotropic patterns are formed where domains of VMT particles align according to the direction of the stress [36]. Upon borax addition, it is assumed that two mechanisms occur. First, borax cross-linking brings PVA chains closer to each other [37], meaning that vermiculite platelets are brought into tighter aggregates, which explains the VMT stacks observed. Then, the anisotropic structures formed during stirring are freezed by crosslinking, and become more pronounced as the shear stress increase with the viscosity of the medium [38], which justifies the preferential orientation of some VMT particles in Figure 3 d. 
These observations thus reveal that VMT particles have different dispersion behaviors depending on the kind of hydrogel and gelation process considered: an isotropic distribution is observed for hydrogel $\mathrm{A}+\mathrm{VMT}$ and hydrogel $\mathrm{A}+\mathrm{VMT}+\mathrm{K}_{2} \mathrm{CO}_{3}$, and an anisotropic distribution is shown for hydrogel $\mathrm{B}+\mathrm{VMT}$ and $\mathrm{C}+\mathrm{VMT}$.

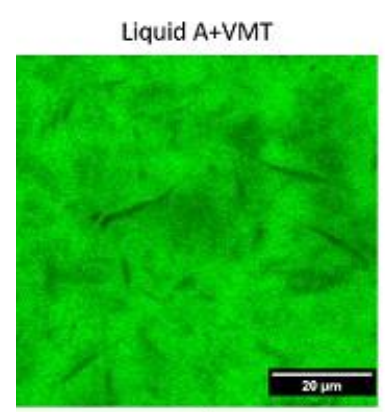

a)

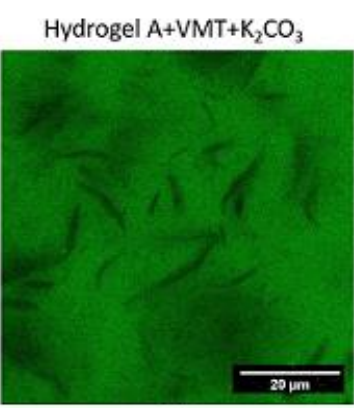

b)

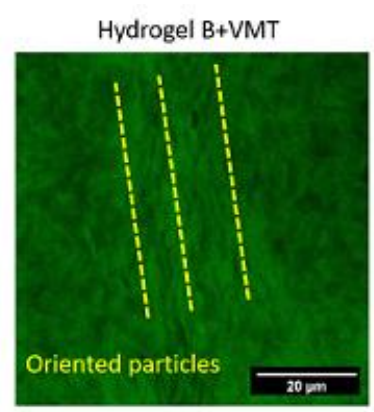

c)

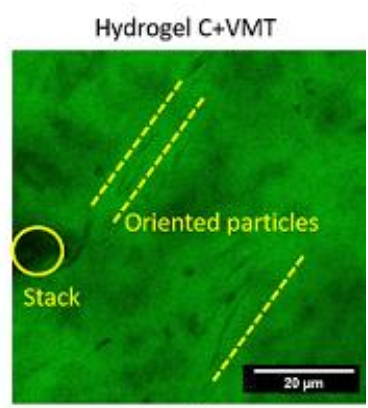

d)

Figure 3. VMT particles dispersion using confocal microscopy (a) Liquid A+VMT, b) Hydrogel $\left.A+V M T+\mathrm{K}_{2} \mathrm{CO}_{3}, c\right)$ Hydrogel B+VMT, d) Hydrogel C+VMT).

\section{Fire behavior}

Figure 4, 5 and Table A1 report the Heat Release Rate (HRR) versus time curves and the fire protection characteristics values, i.e. TTI, THR and pHRR of all samples. As illustrated by figure $4 \mathrm{a}, 3 \mathrm{D}-\mathrm{H}$ A and 3D-H A+VMT both delay the ignition time. Indeed, for these systems, TTI is respectively about 6.5 and 7.5 times longer than the TTI of 3D-air. However, the incorporation of these hydrogels does not improve the THR and pHRR compared to the reference (Figure 5 and Table A1).

On the contrary, for the sandwich multi-materials 3D-H A+VMT $+\mathrm{K}_{2} \mathrm{CO}_{3}$, the incorporation of $\mathrm{K}_{2} \mathrm{CO}_{3}$ leads to drastic improvement of THR and HRR (Figure 4), as it was expected from the behavior of 3D$\mathrm{K}_{2} \mathrm{CO}_{3}$ sat-liquid [13]). It was the reason of the elaboration of this material. The THR of 3D-H $\mathrm{A}+\mathrm{VMT}+\mathrm{K}_{2} \mathrm{CO}_{3}$ are reduced by $88 \%, 66 \%$ and $88 \%$, compared to the reference (3D-air), $3 \mathrm{D}-\mathrm{K}_{2} \mathrm{CO}_{3}$ satliquid and sample with hydrogel A+VMT, respectively. A pHRR reduction of $86 \%, 38 \%$ and $84 \%$ is also measured for sample with hydrogel $\mathrm{A}+\mathrm{VMT}+\mathrm{K}_{2} \mathrm{CO}_{3}$ compared to reference, sample containing $\mathrm{K}_{2} \mathrm{CO}_{3}$ in liquid phase, and 3D-H A+VMT, respectively (Figure 5 and Table A1). However, the TTI is about only slightly increase compared to the reference and the sample containing a saturated $\mathrm{K}_{2} \mathrm{CO}_{3}$ solution (1.9 and 1.5 times longer than 3D-air, 3D- $\mathrm{K}_{2} \mathrm{CO}_{3}$ sat--liquid), and considerably decreased (3.9 lower) compared to 3D-H A+VMT. Consequently, $\mathrm{K}_{2} \mathrm{CO}_{3}$ enables to dramatically reduce the THR and pHRR of the system containing hydrogel A+VMT at the expense of the TTI. However, the gelation process differs from 3D-H A+VMT (where a gelation bath of $\mathrm{CaCl}_{2}$ is used) to $3 \mathrm{D}-\mathrm{H} \mathrm{A}+\mathrm{VMT}+\mathrm{K}_{2} \mathrm{CO}_{3}$ (where gelation is obtained by a cold way process for $24 \mathrm{~h}$ ), what could also be accountable for the variation obtained for TTI measured during MLCC tests. Regarding the second comparison between the system with hydrogel $\mathrm{A}+\mathrm{VMT}+\mathrm{K}_{2} \mathrm{CO}_{3}$ and the system with $\mathrm{K}_{2} \mathrm{CO}_{3}$ in liquid phase, a slight improvement is obtained for the system with hydrogel, compared to the system with $\mathrm{K}_{2} \mathrm{CO}_{3}$ in liquid phase. However, 
as shown in Figure 4 and 5, the difference between the two systems is very low and reveals a very low THR and pHRR in both case.

As it was the case for 3D-H A, the TTI of the system containing hydrogel B (Figure $4 \mathrm{~b}$, Figure 5 and Table A1) is increased by 48 seconds (about 2.8 times longer) than 3D-air, but no reduction of THR and pHRR is obtained ( $28 \%$ and $0.4 \%$, respectively) compared to 3D-air. When VMT is incorporated in hydrogel B, a completely different behavior is observed. Indeed, compared to the reference 3D-air, THR and pHRR of sample containing hydrogel B+VMT are dramatically decreased (by $-86 \%$ and $-64 \%$ respectively), whereas the TTI is rather unchanged with an increase of 5 seconds.

Regarding 3D-H C, no improvement is brought in terms of TTI, THR (-2\%) and pHRR (-3\%) compared to the reference. Figure $4 \mathrm{c}$ shows a quick ignition of sample, with a fast extinction probably due to the water emission from hydrogel, and a second inflammation with a high heat release until the end of the test. However, when VMT is incorporated in hydrogel $\mathrm{C}$, an unexpected fire behavior is observed. The THR and pHRR difference between 3D-H C+VMT and 3D-air corresponds to $-82 \%$ and $-36 \%$, respectively. Regarding the TTI, a slight increase of 12 seconds was measured that is about 1.5 times higher than 3D-air. Therefore, as with 3D-H B+VMT, the incorporation of VMT in hydrogel C provides the formation a very efficient fire barrier exhibiting an extremely low THR value.

Figure $4 \mathrm{~d}$ reports the temperature as a function of time curves measured at the backside of the reference (3D-air), and of the 3D polymer samples with hydrogel inside. First, it was observed that all systems reach a steady state at $500^{\circ} \mathrm{C}$ after $700 \mathrm{~s}$ to $1500 \mathrm{~s}$ of fire test. Indeed, the steady state of hydrogel containing systems is reached at longer times than for 3D-air. Moreover, for hydrogel containing systems, a plateau at $100^{\circ} \mathrm{C}$ is registered whereas it is not obtained for the reference. This plateau is attributed to the water released during the MLCC test. Finally, a slower temperature rise is measured for hydrogel containing systems than for 3D-air and thus the decomposition of the material is delayed.

Therefore, the incorporation of hydrogel A and B in the 3D samples delays the TTI, but has no influence on THR and pHRR. No improvement is observed for hydrogel C. However, when VMT is added in hydrogel B and C an unexpected reduction of THR (> 80\%) and pHRR (64\% and 36\% respectively) is measured, as opposed to hydrogel A where no significant decrease is observed. The incorporation of $\mathrm{K}_{2} \mathrm{CO}_{3}$ in hydrogel A+VMT allows to reach very low THR and pHRR, at the expense of TTI. To explain these fire behavior differences, visual observations of top and cross-section of residues after MLCC test were carried out and gathered in Figure 6. 

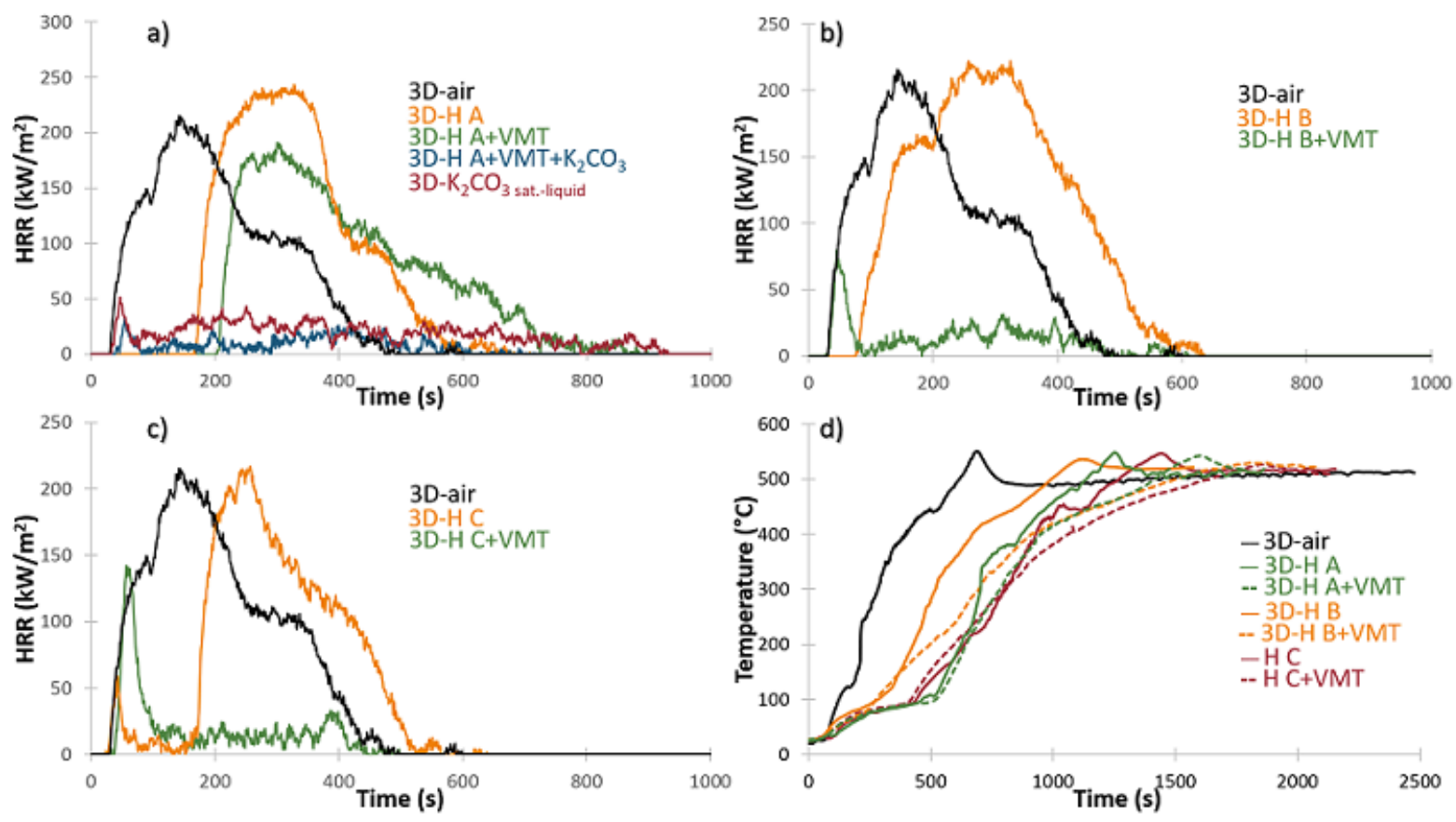

Figure 4. Fire behavior of each system studied (a) for systems with hydrogel A, b) for systems with hydrogel B, c) for systems with hydrogel $C, d$ ) evolution of temperature versus time for all systems studied

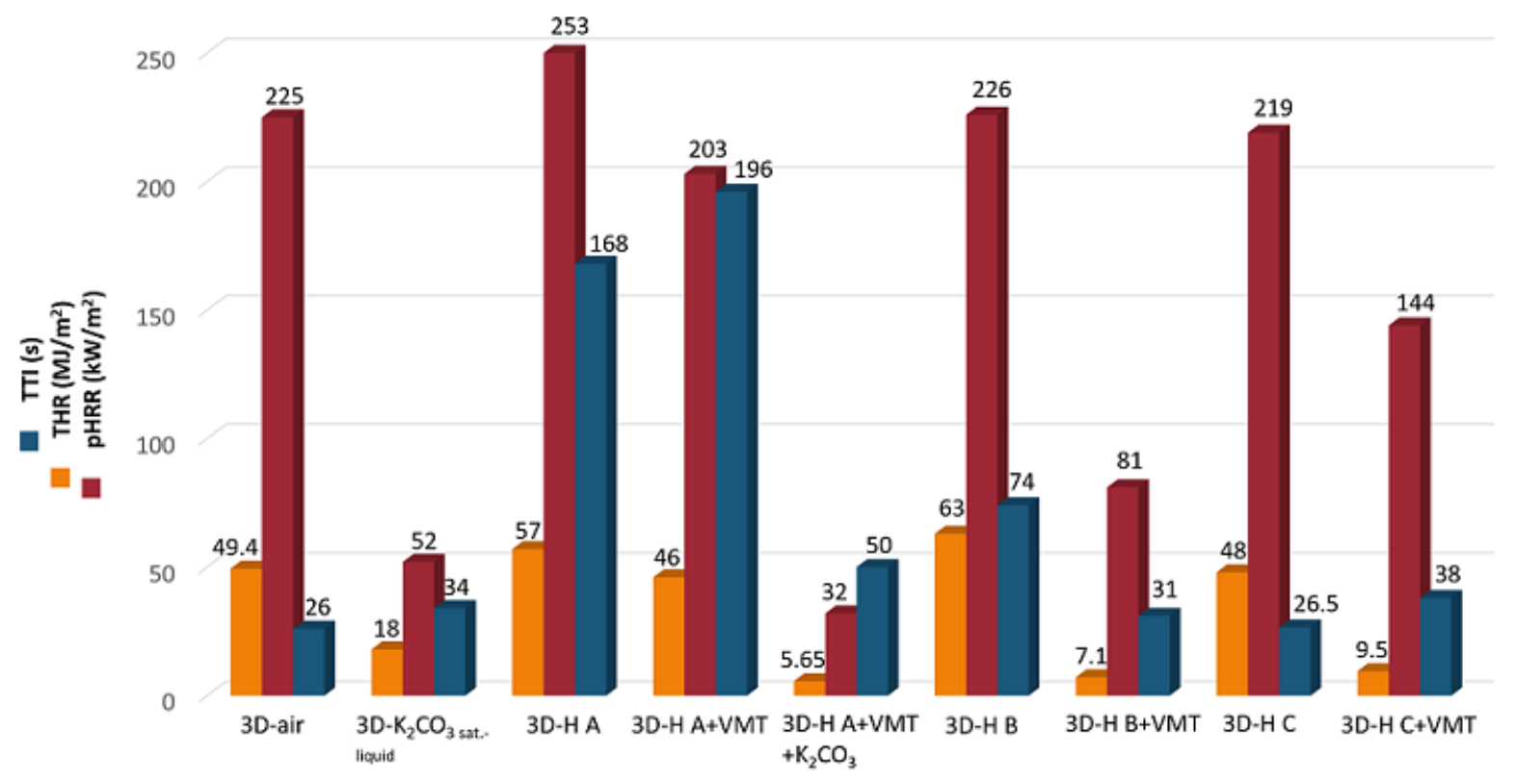

Figure 5. Fire protection performances values of each system studied

For 3D-air, 3D-H A, 3D-H B, and 3D-H C, similar residues are observed. An agglomerate of white powder (alumina resulting from the dehydration of ATH) is obtained at the end of the MLCC test (Figure $6 \mathrm{a}, \mathrm{b}, \mathrm{e}, \mathrm{g})$.

For 3D-H A+VMT, a grey residue is obtained and the initial structure is partly retained. Additionally, powder agglomerates can once again be seen (Figure $6 \mathrm{c}$ ). For $3 \mathrm{D}-\mathrm{H} \mathrm{A}+\mathrm{VMT}+\mathrm{K}_{2} \mathrm{CO}_{3}$ residue, the structure of the residue is maintained but is very brittle. Voids and polymer core can be observed, as illustrated in figure $6 \mathrm{~d}$. When VMT is added in the two other hydrogels (hydrogel B+VMT (Figure $6 \mathrm{f}$ ) 
and hydrogel C+VMT (Figure $6 \mathrm{~h}$ ), the initial structure is kept at the end of MLCC test. The two skins and the core with voids inside can be distinguished. A white shell is observed, with a brown polymer core in the middle. The brown color could correspond to a mix of alumina residue and VMT network. To understand and explain the difference in terms of fire protection performances between systems with hydrogels containing $\mathrm{K}_{2} \mathrm{CO}_{3}$ and/or VMT: i) the VMT orientation and distribution in residues obtained after MLCC test were observed using EPMA imaging and ii) XRD analysis were also done to highlight if crystalline network modification occurs during the heat exposure.
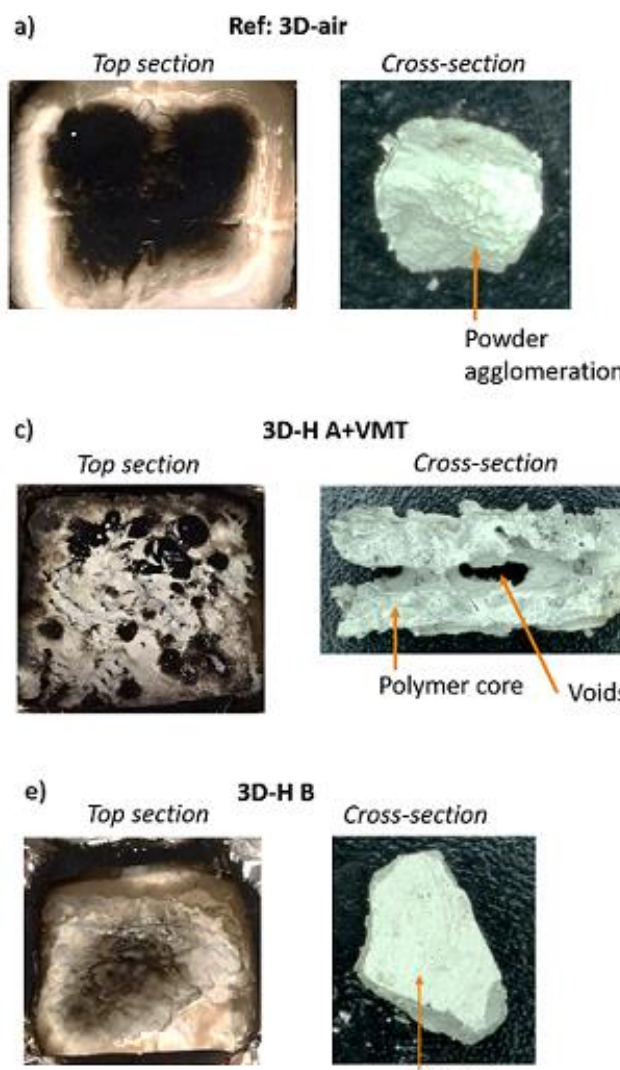

Powder agglomeration

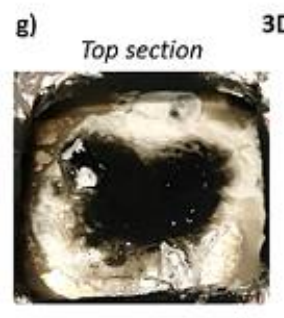

H C

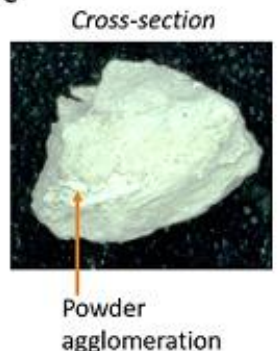

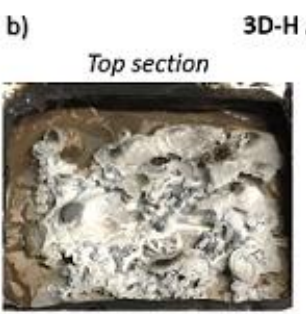

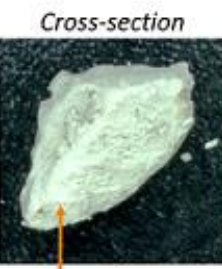

Powder

agglomeration
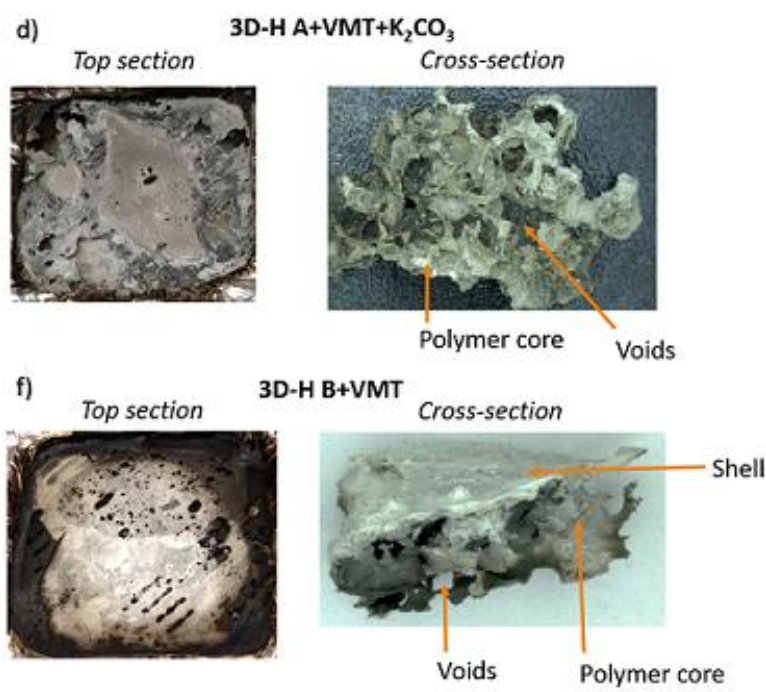

h)

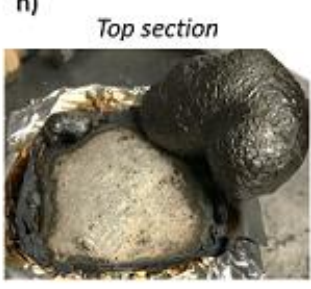

3D-H C+VMT

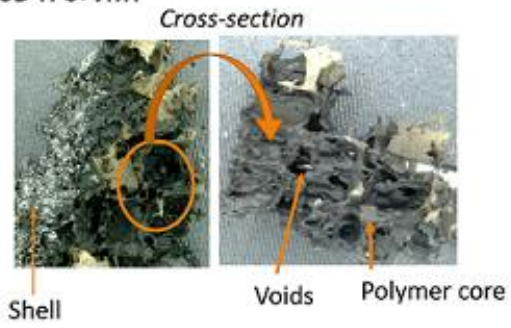

Figure 6. Top and cross-section pictures of residue after MLCC test (a) 3D-air, b) 3D-H A, c) 3D-HA+VMT, d) 3D-H $\left.\left.\left.\left.\left.A+V M T+K_{2} C_{3}, e\right) 3 D-H B, f\right) 3 D-H B+V M T, g\right) 3 D-H C, h\right) 3 D-H C+V M T\right)$. 


\section{Mechanism investigation}

A first investigation is done on the heat release rate difference between samples with hydrogel A+VMT, $\mathrm{B}+\mathrm{VMT}$ and $\mathrm{C}+\mathrm{VMT}$. Then, a particular attention will be paid to the effect of $\mathrm{K}_{2} \mathrm{CO}_{3}$ in hydrogel $\mathrm{A}+\mathrm{VMT}$

\subsection{Clay influence investigation on the fireproofing}

\subsubsection{EPMA observations}

Figures 7, 8 and 9 illustrate $\mathrm{Al}, \mathrm{Mg}$ and $\mathrm{Fe}$ distribution for the reference (3D-air) and for the system with hydrogel $\mathrm{A}$ and $\mathrm{A}+\mathrm{VMT}$, the system with hydrogel $\mathrm{B}$ and $\mathrm{B}+\mathrm{VMT}$ and the hydrogel $\mathrm{C}$ and $\mathrm{C}+\mathrm{VMT}$, respectively, using EPMA analysis. Al element distribution was observed to identify alumina formed by the 3D printed polymer (EVA/ATH (30 wt.-\%)) degradation and Fe and $\mathrm{Mg}$ were analyzed to determine the VMT particles distribution after MLCC tests. First, it was observed that the reference and all systems without VMT were only composed of alumina, as Al-mappings illustrated (Figures $7 \mathrm{a}_{1}, 7$ $\mathrm{a}_{2}, 8 \mathrm{a}_{1}, 8 \mathrm{a}_{2}, 9 \mathrm{a}_{1}$ and $9 \mathrm{a}_{2}$ ). No Fe, $\mathrm{Mg}$ and $\mathrm{K}$ were identified on the mapping, and thus, Fe/Mg and $\mathrm{K}$ mappings of sample with air, hydrogel A, hydrogel B and hydrogel C were not shown. For the samples containing VMT, Mg and Fe-mappings highlight a difference of VMT distribution according to the hydrogel considered. Indeed, for 3D-H A+VMT, VMT particles form clusters with some voids between each particle (Figures 7 b, 7 c, 7 d and Figure A1). On the opposite, VMT particles line up and tightly imbricate to form a protective layer for 3D-H B+VMT (Figures $8 \mathrm{~b}, 8 \mathrm{c}, 8 \mathrm{~d}$ and Figure A2) and 3D-H $\mathrm{C}+\mathrm{VMT}$ (Figures 9 b, 9 c, $9 \mathrm{~d}$ and Figure A3). Moreover, Al-mappings and Mg or Fe-mappings reveal that $\mathrm{Al}$ surrounds the VMT clusters in the case of $3 \mathrm{D}-\mathrm{H} \mathrm{A}+\mathrm{VMT}$ or the tightly imbricated VMT networks in the case of sample with hydrogel $\mathrm{B}+\mathrm{VMT}$ and $\mathrm{C}+\mathrm{VMT}$. It is also noteworthy that the $\mathrm{Al}$, $\mathrm{Fe}$ and Mg-mappings of 3D-H B+VMT and 3D-H C+VMT are similar, which makes sense because of the similar initial chemical composition and the similar fire performance.

The distribution difference between VMT particles reveals that VMT particles have a physical effect during MLCC tests, which explains the difference in term of fire protection performances. Indeed, for the system with hydrogel $\mathrm{B}+\mathrm{VMT}$, and $\mathrm{C}+\mathrm{VMT}$, the VMT particles are organized and tightly imbricated to form a protective layer, which reduces the mass transfer in the system (the gas evolution is limited because of the high tortuosity of the layer), and thus the heat release rate [22]. In comparison, for the system with hydrogel A+VMT, some voids can be distinguished between VMT particles, and therefore mass transfer is not limited and so, the released gases feeds the flame.

To go further in the investigation of the mechanism, a study of the crystalline structure of the residue and thus the crystalline network evolution was carried out using XRD analyses. 


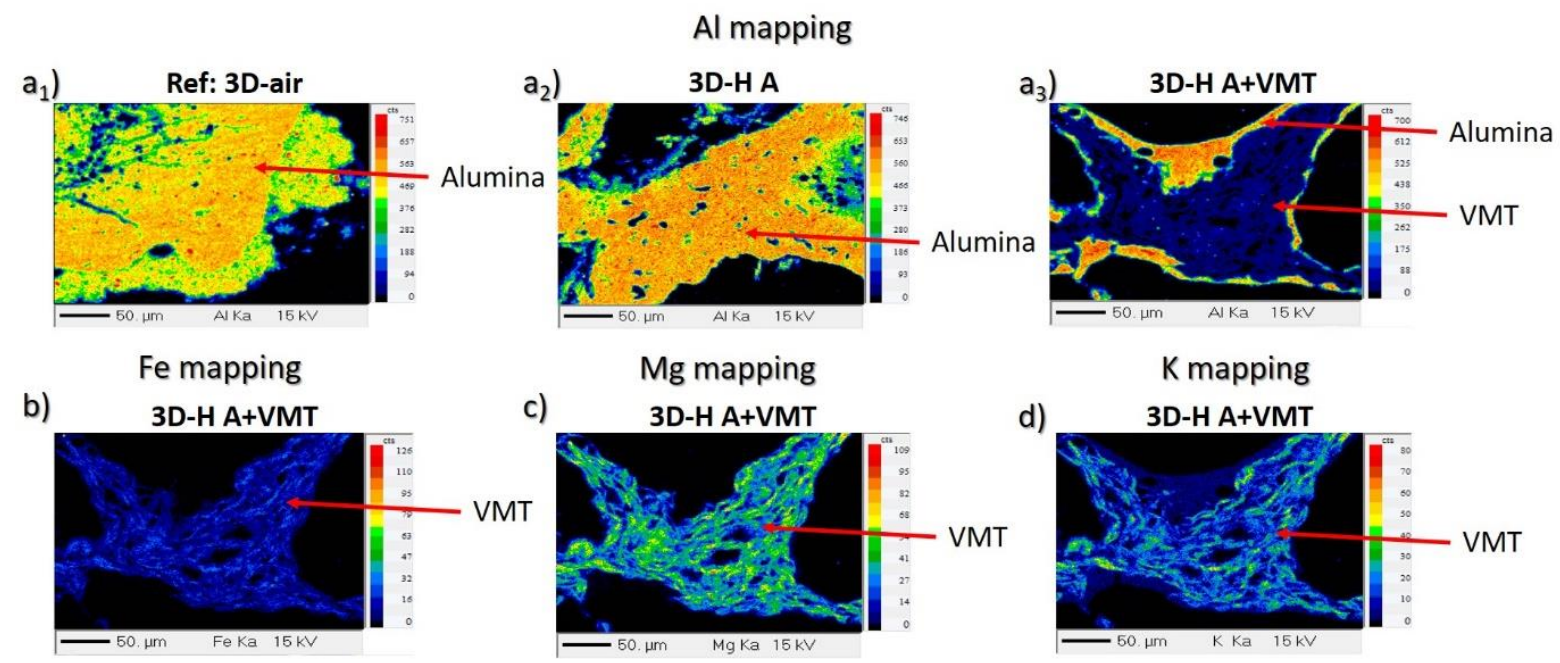

Figure 7. X-rays mappings of (al) Al element of 3D-air, a2) Al element of $\left.3 D-H A, a_{3}\right)$ Al element of $\left.3 D-H A+V M T, b\right) F e$ element of $3 D-H A+V M T, c) M g$ element of $3 D-H A+V M T, d)$ K element of $3 D-H A+V M T)$ cross-sections, using EPMA measurements.

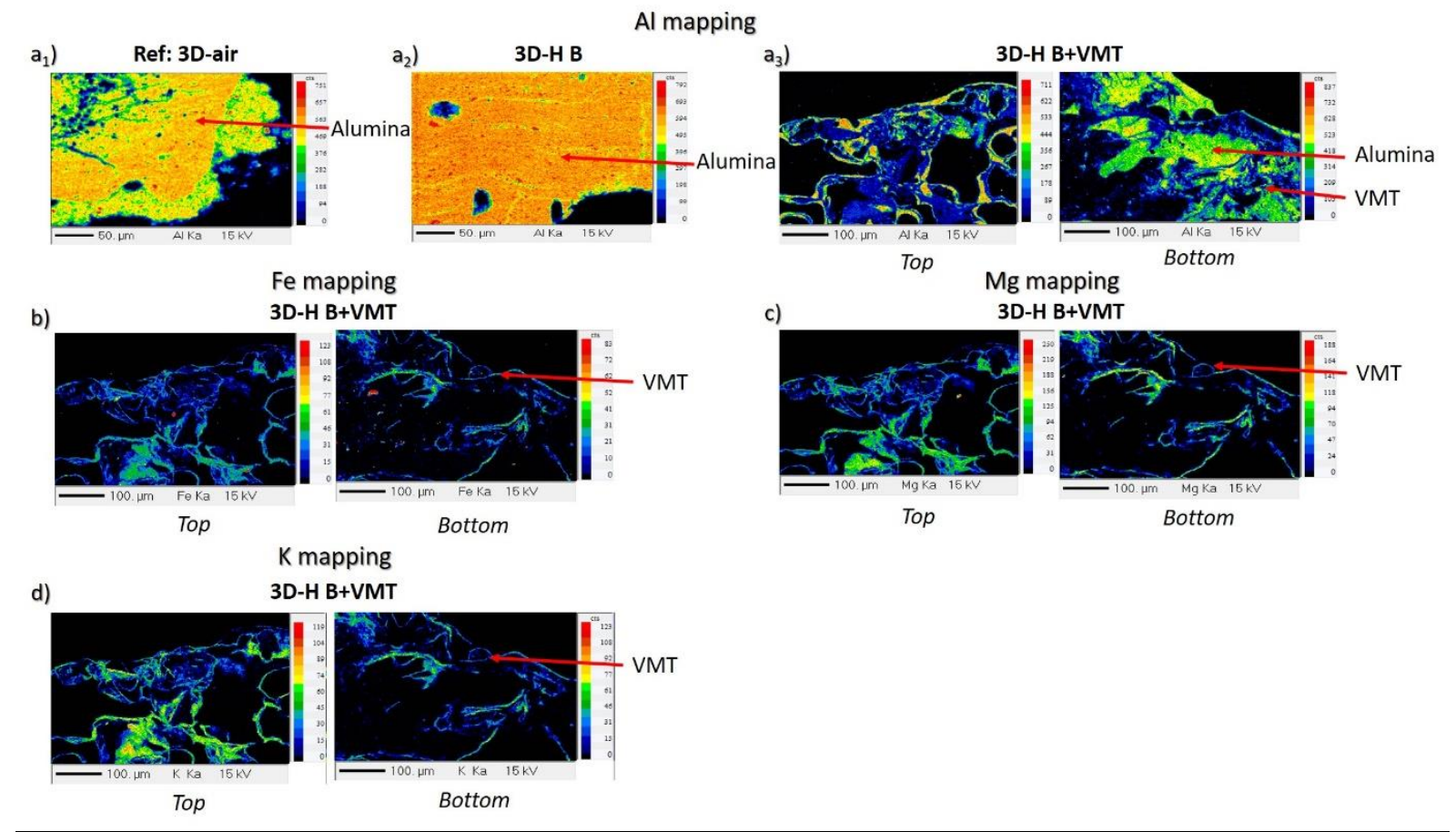

Figure 8. X-rays mappings of $\left(a_{1}\right)$ Al element of $3 D$-air, $\left.a_{2}\right)$ Al element of $\left.3 D-H B, a_{3}\right)$ Al element of $\left.3 D-H B+V M T, b\right) F e$ element of $3 D-H B+V M T$, c) Mg element of $3 D-H B+V M T, d)$ K element of $3 D-H B+V M T)$ cross-sections, using EPMA measurements. 


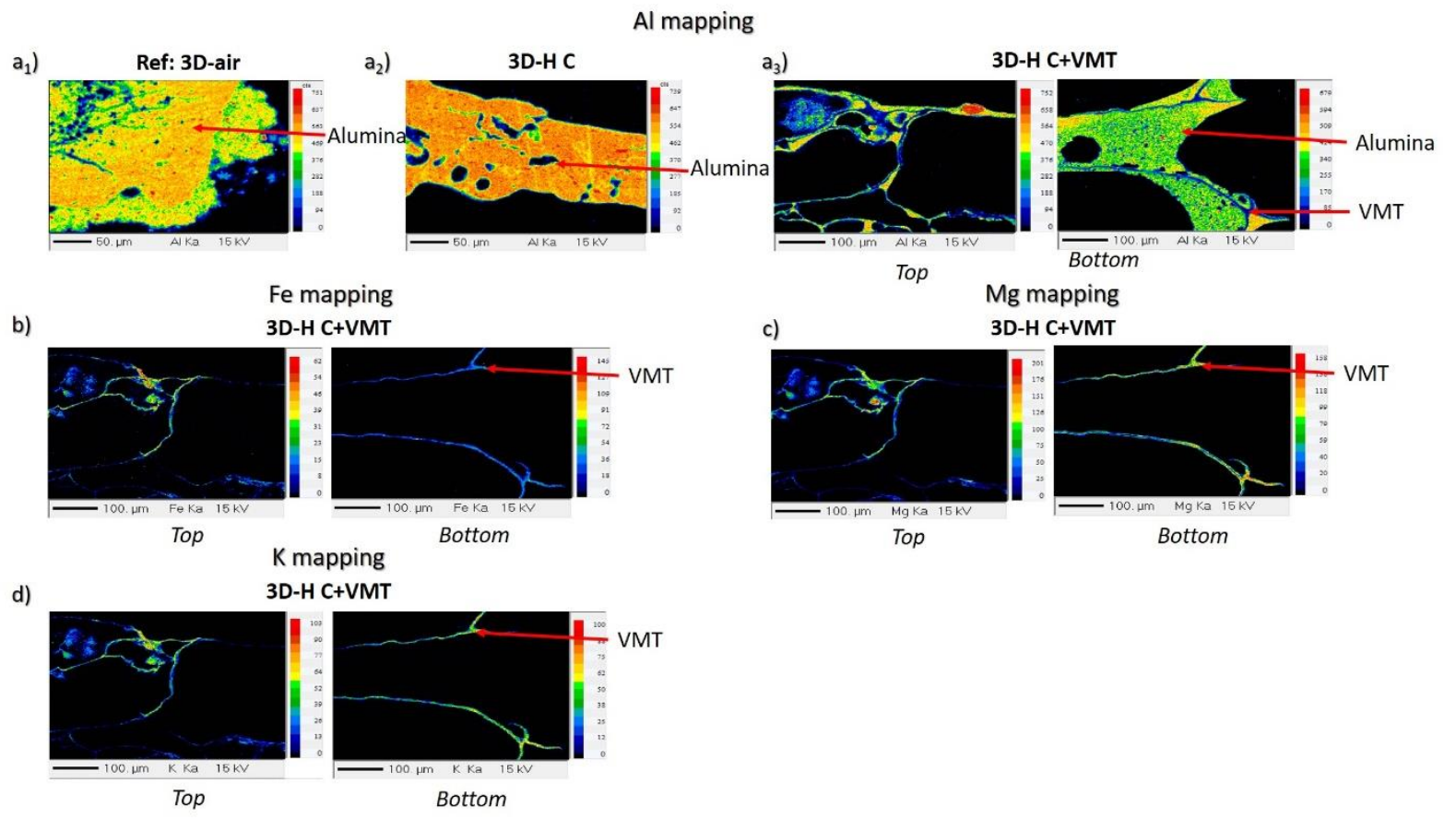

Figure 9. X-rays mappings of ( $\left.a_{1}\right)$ Al element of 3D-air, $\left.a_{2}\right)$ Al element of $\left.3 D-H C, a_{3}\right)$ Al element of $\left.3 D-H C+V M T, b\right) F e$ element of $3 D-H C+V M T, c) M g$ element of $3 D-H C+V M T, d)$ K element of $3 D-H C+V M T)$ cross-sections, using EPMA measurements.

\subsection{2. $X R D$ analysis}

Figure 10 gathers the XRD scans of residues 3D-H A+VMT, 3D-H B+VMT, and 3D-H C+VMT. On all XRD patterns, similar peaks can be observed attributed to the presence of alumina and boehmite crystalline phases according to the database used for peaks identification. Indeed, the cubic alumina $\mathrm{Al}_{2} \mathrm{O}_{3}$ crystalline phase resulting from the $\mathrm{ATH}$ decomposition during the fire testing (Figure 10 and Figure A4) is detected by two peaks at $2 \theta$ around $60^{\circ}$ to $67^{\circ}$. Moreover, a peak at $2 \theta$ value of $14^{\circ}$ is attributed to boehmite $\mathrm{AlO}(\mathrm{OH})$ crystalline phase (Figure A4). This peak also results from ATH dehydration during the test.

Then, a peak at $2 \theta=30^{\circ}$ (Figure 10) is observed for the residue of 3D-H A+VMT, as opposed to other residues where no peak is visible. It corresponds to calcite $\left(\mathrm{CaCO}_{3}\right)$ crystalline phase, and results from the gelation process of hydrogel A cross-linked using calcium ions. Thus, during the fire test, hydrogel A decompose and $\mathrm{CaCO}_{3}$ is formed.

Finally, other peaks (in the large region at $2 \theta$ values between $34^{\circ}$ to $50^{\circ}$, from $2 \theta=5^{\circ}$ to $10^{\circ}$ and from $2 \theta=26^{\circ}$ to $30^{\circ}$ ) are detected and mainly correspond to VMT and more specifically to the phlogopite $\mathrm{KMg}_{3}\left(\mathrm{Si}_{3} \mathrm{Al}\right) \mathrm{O}_{10}(\mathrm{OH})_{2}$ crystalline phase (Figure 10 and Figure A4). Slight differences of position are observed between residues. The peaks identified in two sections of the XRD patterns from $2 \theta=5^{\circ}$ to $10^{\circ}$ and from $2 \theta=26^{\circ}$ to $30^{\circ}$ correspond to the (001) crystallographic plane of VMT. Their modifications reveal changes in the parameter $\mathrm{c}$ of the crystal structure corresponding to the d-spacing between the VMT layers [39], [40]. The peak between 5 and $10^{\circ}$ of 3D-H A+VMT residue is detected at a higher $2 \theta$ value than the peak obtained for 3D-H B+VMT and 3D-H C+VMT obtained at the same position (Figure 
10). The opposite is observed between $26^{\circ}$ to $30^{\circ}$ where the peak of $3 \mathrm{D}-\mathrm{H} \mathrm{A}+\mathrm{VMT}$ residue is detected at lower $2 \theta$ value than the one of the two other residues.

To explain the variations of d-spacing, and highlight their influence against temperature, a high temperature X-ray diffraction of VMT was done (Figure 11).

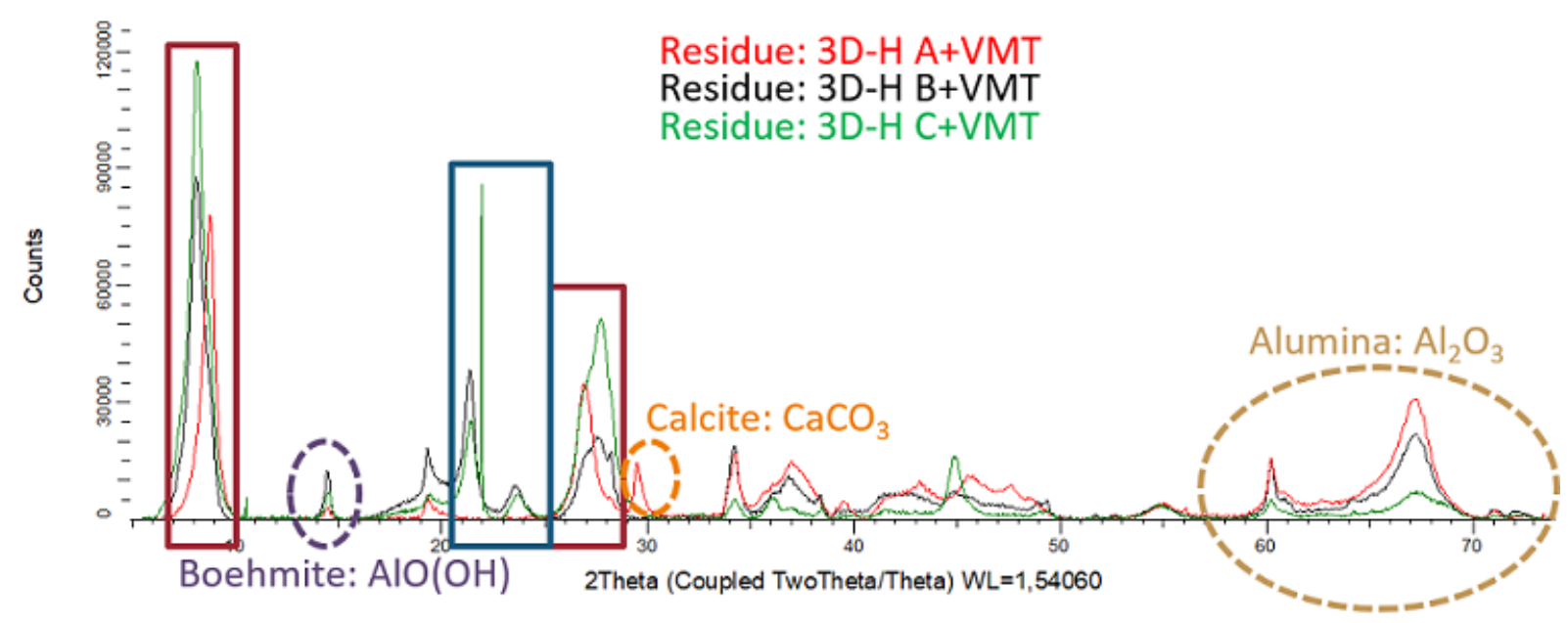

Figure 10. XRD of residues: $3 D-H A+V M T, 3 D-H B+V M T$, and $3 D-H C+V M T$.

Figure 11 describes the evolution of VMT crystalline phase as a function of temperature (from $50^{\circ} \mathrm{C}$ to $1000^{\circ} \mathrm{C}$ ). Two phase transitions are clearly observed at $150^{\circ} \mathrm{C}$ and $900^{\circ} \mathrm{C}$. Two $2 \theta$ regions (from $5^{\circ}$ to $10^{\circ}$ and from $26^{\circ}$ to $30^{\circ}$ ) are mainly impacted by these phase transition. The position and the shape of these peaks changes as a function of temperature. These phase transitions are due to the different hydration state of the VMT foils. For the first phase transition at $150^{\circ} \mathrm{C}$, the water adsorbed on the surface and the water between interlayer is released, leading to a first crystalline transition, and thus a modification of the interlayer stacking distance [39], [40]. The second transition at $900^{\circ} \mathrm{C}$ provokes a slight increase of interlayer spacing (Figure 11) not clearly explain in literature. It is assumed that this second transition arises from a structural changed at high temperature [41]. For the residue 3D-H $\mathrm{B}+\mathrm{VMT}$ and residue $3 \mathrm{D}-\mathrm{H} \mathrm{C}+\mathrm{VMT}$, the same peaks positions (from $5^{\circ}$ to $10^{\circ}$ and from $26^{\circ}$ to $30^{\circ}$ ) are observed, and are similar to the ones measured for VMT at $100^{\circ} \mathrm{C}$. Furthermore, the same observation (peaks ranging from $5^{\circ}$ to $10^{\circ}$ and from $26^{\circ}$ to $30^{\circ}$ ) can be done for residue $3 \mathrm{D}-\mathrm{H} \mathrm{A}+\mathrm{VMT}$ and for VMT at $800^{\circ} \mathrm{C}$. These crystalline phase transitions and thus the interlayer stacking distance differences can be explained by the temperature difference reached on the sample surface. Indeed, due to the lower fire protective performances and thus to the presence of flame during MLCC tests, 3D-H A+VMT is submitted to a higher temperature on the top compared to samples with hydrogel B+VMT and C+VMT where the flame is rapidly extinguished.

Moreover, in Figure 10, two peaks at $21.4^{\circ}$ and $23.6^{\circ}$ are identified for residues 3D-H B+VMT and 3D$\mathrm{H} \mathrm{C}+\mathrm{VMT}$, as opposed to the residue of $3 \mathrm{D}-\mathrm{H} \mathrm{A}+\mathrm{VMT}$ where no peak is visible. By correlating Figure 10 and Figure 11, it is possible to suppose that both peaks do not come from VMT. Indeed, no peak is observed in Figure 11. Therefore, it is assumed that this phase corresponds to an organic phase from the 
polymer decomposition during the heat exposure. Indeed, a carbonaceous phase is observed in XRD diagram between $20^{\circ}$ to $25^{\circ}$, fully discussed in some previous papers as for example [42]. Based on figure 10 and the fire protective performances, this assumption makes sense because of the low heat release rate of $3 \mathrm{D}-\mathrm{H} \mathrm{B}+\mathrm{VMT}$ and $3 \mathrm{D}-\mathrm{H} \mathrm{C}+\mathrm{VMT}$, compared to $3 \mathrm{D}-\mathrm{H} \mathrm{A}+\mathrm{VMT}$. It suggests that the carbonaceous phase has time to organize for systems with hydrogel $\mathrm{B}+\mathrm{VMT}$ and $\mathrm{C}+\mathrm{VMT}$ compared to system with hydrogel A+VMT, which is exposed to flame and higher temperature.

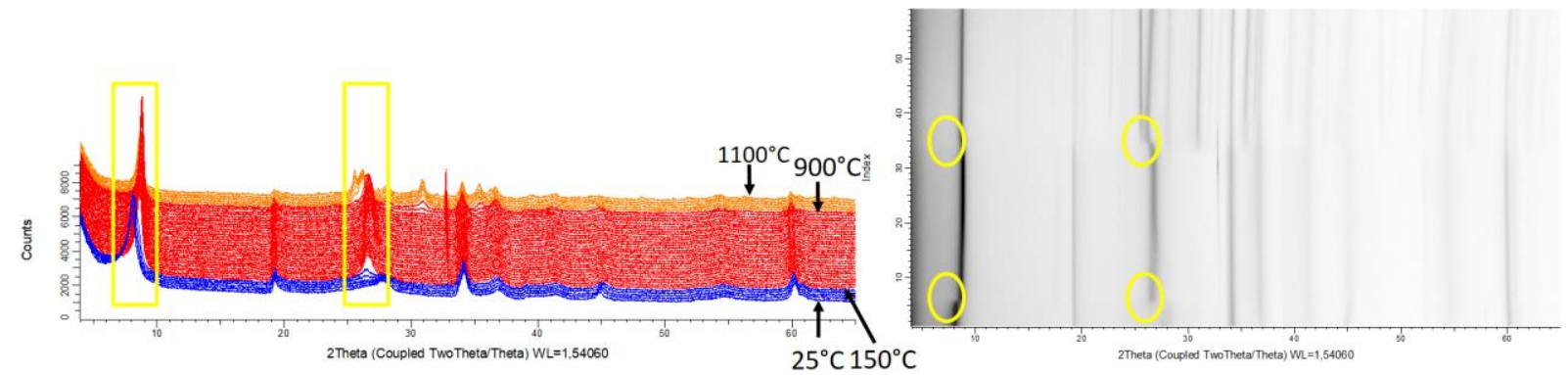

a) High Temperature X-ray Diffraction 3D view of VMT

b) High Temperature X-ray Diffraction 2D view of VMT

Figure 11. High Temperature X-ray Diffraction of VMT.

XRD results pointed out the absence of chemical interaction between the components of the systems.

The variation of peaks attributed to VMT is due to dehydration processes related to the difference in heat exposure time between the different samples, which have a consequence on the interlayer distance. As a conclusion, VMT has seemingly no influence on the degradation of other constituents. Therefore, its action is purely a physical process rather than a chemical one, which confirms the previous EPMA observations.

\section{2. $\mathrm{K}_{2} \mathrm{CO}_{3}$ influence on fireproofing}

\subsubsection{Gas phase mechanism}

$\mathrm{K}_{2} \mathrm{CO}_{3}$ has been reported to act both in condensed and gas phase [13]. In this study, figure 12 clearly highlights the presence of potassium into the flame (purple color) for the system containing hydrogel $\mathrm{A}+\mathrm{VMT}+\mathrm{K}_{2} \mathrm{CO}_{3}$ compared to the classical yellowish flame obtained for the system containing only hydrogel A+VMT [13]. Indeed, the coloration of flame is caused by the de-excitation of thermally excited electrons, which provokes the emission of a photon (light) with a precise wavelength depending on the electronic structure of the chemical element ( $\mathrm{K}+$ leads to a purple flame coloration).

Therefore, before fire testing, $\mathrm{K}_{2} \mathrm{CO}_{3}$ is dissociated in the water of hydrogel according to this reaction: $\mathrm{K}_{2} \mathrm{CO}_{3(\mathrm{~s})}+\mathrm{H}_{2} \mathrm{O} \rightarrow \mathrm{KOH}+\mathrm{KHCO}_{3}$. During MLCC tests, when the sample ignites, the solution reaches its boiling temperature and the solution is vaporized into the flame, leading to a purple flame observation because of the presence of potassium (Figure 12). As flame temperature is higher than $\mathrm{KHCO}_{3}$ decomposition temperature, $\mathrm{KHCO}_{3}$ decarbonizes according to the following reaction: $\mathrm{KHCO}_{3} \rightarrow \mathrm{CO}_{2}$ (g) $+\mathrm{H}_{2} \mathrm{O}_{(\mathrm{g})}+\mathrm{K}_{2} \mathrm{CO}_{3}$ (s). $\mathrm{CO}_{2}$ and $\mathrm{H}_{2} \mathrm{O}$, two nonflammable gases, are produced, which dilute the flame and provoke its fast extinguishment, thus reducing the heat release rate during the MLCC test. Therefore, 
the gas phase mechanism in hydrogel phase is similar to those observed in liquid phase (solution of $\left.\mathrm{K}_{2} \mathrm{CO}_{3}\right)$ [13].

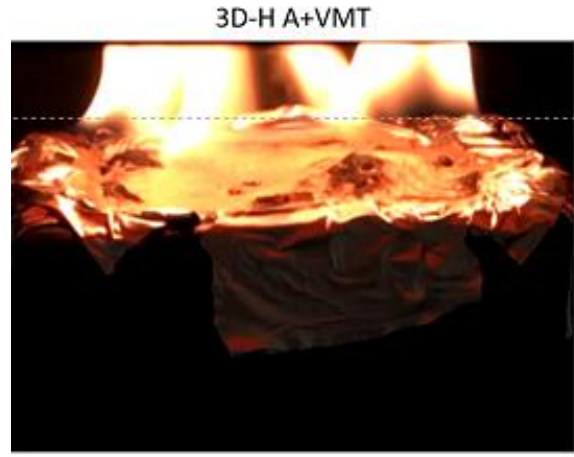

a)

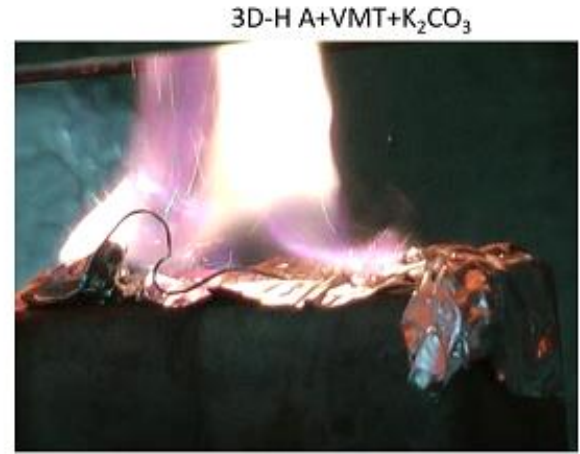

b)

Figure 12. Visual observation of flame color (a) for $3 \mathrm{D}-\mathrm{H} \mathrm{A}+\mathrm{VMT}, \mathrm{b}$ ) $3 \mathrm{D}-\mathrm{H} \mathrm{A}+\mathrm{VMT}+\mathrm{K}_{2} \mathrm{CO}_{3}$ )

\subsubsection{Condensed phase mechanism}

The condensed phase mechanism in presence of $\mathrm{K}_{2} \mathrm{CO}_{3}$ was also investigated. XRD analyses were carried out on the $3 \mathrm{D}-\mathrm{H} \mathrm{A}+\mathrm{VMT}+\mathrm{K}_{2} \mathrm{CO}_{3}$ residue and compared to those of $3 \mathrm{D}-\mathrm{K}_{2} \mathrm{CO}_{3}$ sat-liquid residue (Figure A5). As illustrated by figure 13, the same $\left(\mathrm{KAl}\left(\mathrm{CO}_{3}\right)(\mathrm{OH})_{2}\right)$ crystalline phase was identified. Additionally, other crystalline phases attributed to VMT (phlogopite) and alumina $\left(\mathrm{Al}_{2} \mathrm{O}_{3}\right)$ were observed on the XRD diagram. Therefore, as previously described, when the hydrogel $\mathrm{A}+\mathrm{VMT}+\mathrm{K}_{2} \mathrm{CO}_{3}$ is vaporized into the flame, the following reaction occurs: $2 \mathrm{KHCO}_{3} \rightarrow \mathrm{K}_{2} \mathrm{CO}_{3}(\mathrm{~s})+\mathrm{CO}_{2}(\mathrm{~g})+\mathrm{H}_{2} \mathrm{O}$ (g) . The $\mathrm{K}_{2} \mathrm{CO}_{3}$ formed reacts with the ATH contained in EVA during the degradation, which leads to the formation of the crystalline phase $\mathrm{KAl}\left(\mathrm{CO}_{3}\right)(\mathrm{OH})_{2}$ identified using XRD analysis.

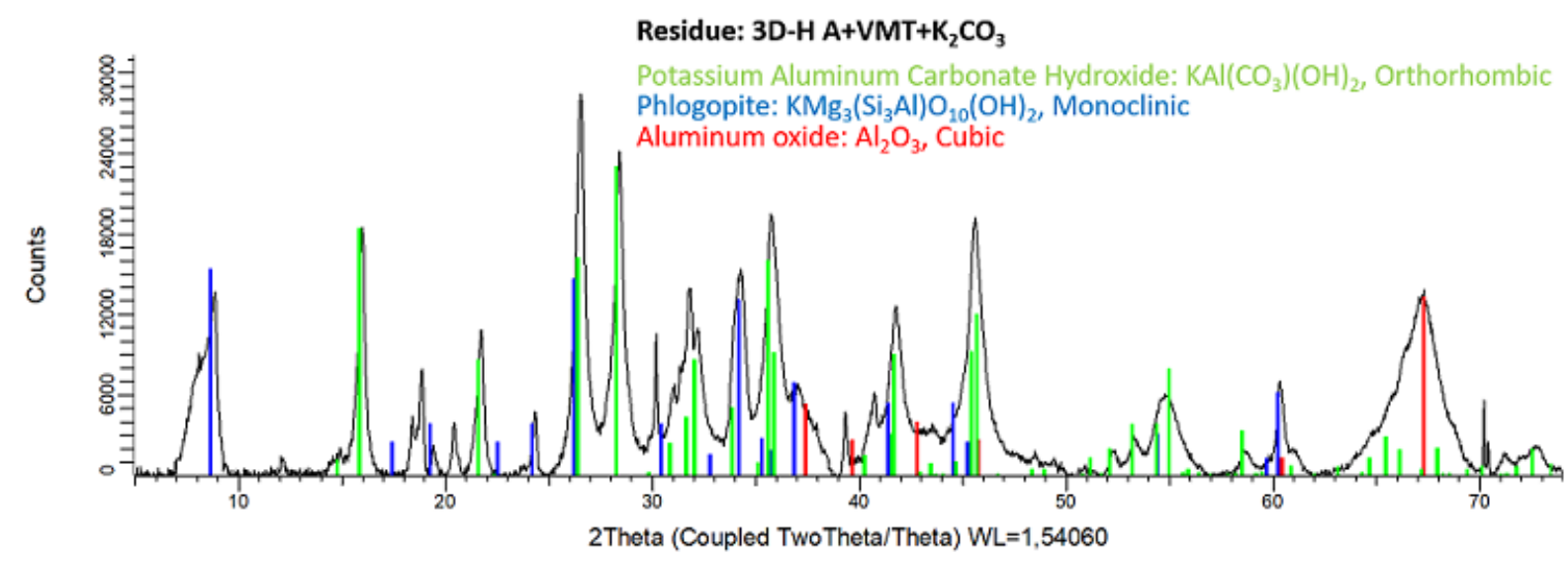

Figure 13. XRD of residue 3D- $\mathrm{H} A+V M T+\mathrm{K}_{2} \mathrm{CO}_{3}$

To determine the action of the VMT in the fire protective mechanism of the system containing hydrogel $\mathrm{A}+\mathrm{VMT}+\mathrm{K}_{2} \mathrm{CO}_{3}, \mathrm{Al}, \mathrm{Fe}$ and $\mathrm{Mg}$ mappings were carried out using EPMA. As for the system with hydrogel A+VMT, no stack of VMT is observed. VMT particles form clusters with some voids between 
VMT particles (Figure 14 and Figure A6). Therefore, the efficiency of the VMT barrier is not as high as those formed by the systems containing hydrogel B+VMT or hydrogel C+VMT. However, VMT particles organize anyway and form a physical thermal barrier (less efficient than for system with hydrogel $\mathrm{B}+\mathrm{VMT}$ and $\mathrm{C}+\mathrm{VMT}$, but still performant) which is added to $\mathrm{K}_{2} \mathrm{CO}_{3}$ thermal insulation action. Moreover, the crystalline phase composed of $\mathrm{K}$ and $\mathrm{Al}$ is confirmed on $\mathrm{K}$ and $\mathrm{Al}$ mappings. Indeed, a predominant phase (in yellow and green on $\mathrm{Al}$ (figure $14 \mathrm{a}_{2}$ ) and $\mathrm{K}$ (figure $14 \mathrm{~d}_{2}$ ) mappings, respectively) is observed and located in the same part of the mapping.

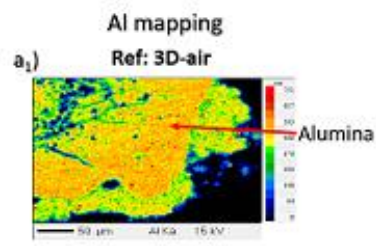

a) $3 D-\mathrm{H} A+\mathrm{VMT}+\mathrm{K}_{2} \mathrm{CO}_{3}$

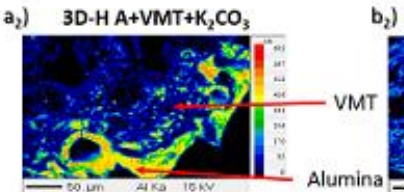

MT

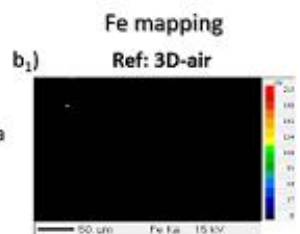

$3 \mathrm{D}-\mathrm{H} \mathrm{A}+\mathrm{VMT}+\mathrm{K}_{2} \mathrm{CO}_{3}$

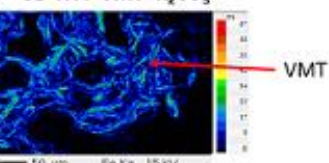

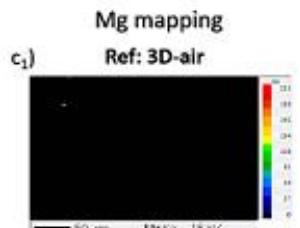

c) $3 \mathrm{D} \cdot \mathrm{H} \mathrm{A}+\mathrm{VMT}+\mathrm{K}_{2} \mathrm{CO}_{3}$

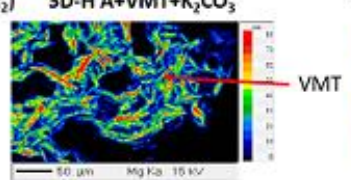

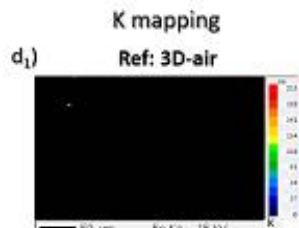

d 3 ) 3 - $\cdot \mathrm{H} A+\mathrm{VMT}+\mathrm{K}_{2} \mathrm{CO}_{3}$

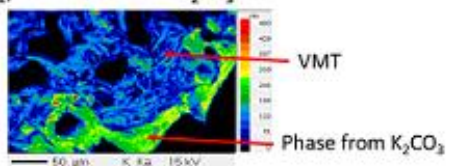

Figure 14. Cross-section X ray mapping in a) Al element, b) Fe element, c) Mg element, d) K element, using EPMA measurements of (1) $3 D$-air, 2) $3 \mathrm{D}-\mathrm{H} \mathrm{A}+\mathrm{VMT}+\mathrm{K}_{2} \mathrm{CO}_{3}$ ).

Therefore, the efficient fire protective performance of $3 \mathrm{D}-\mathrm{H} \mathrm{A}+\mathrm{VMT}+\mathrm{K}_{2} \mathrm{CO}_{3}$ is explained by the combination of two phenomena: i) mostly due to the action of $\mathrm{K}_{2} \mathrm{CO}_{3}$ in gas and condensed phase (fully described in paper [13]), and also with ii) the physical action of VMT particles contained in hydrogel.

\section{General discussion}

The mechanisms of action of the various systems studied in this work are summarized in Figure 15 and Figure 16. When 3D-H A (Figure 16 a), 3D-H B (Figure 15 a) and 3D-H C (Figure $15 \mathrm{c}$ ) are exposed under a radiative heat flux, the top section of the materials (a $0.6 \mathrm{~mm}$-thick plate of EVA/ATH) starts to decompose as the hydrogel slowly releases water. As a consequence, a long TTI is measured compared to the reference (3D-air). However, when all water is released, the material burns and decomposes, with a high heat release rate. In comparison with system using water as sole liquid phase [13], the use of hydrogel phase allows to reach longer TTI. Therefore, it is assumed that hydrogel phase allows to better control the water releasing during the MLCC test by spreading its release over a longer time [13]. Moreover, as previously mentioned, the only difference between hydrogel A, hydrogel B and hydrogel $\mathrm{C}$ is the gelation process: hydrogel $\mathrm{C}$ contains borax which provokes a swelling phenomenon, as it is illustrated in Figure $15 \mathrm{c}$, hydrogel A is formed using a cross-linking gelation bath, and hydrogel $\mathrm{B}$ is obtained by cooling at room temperature. Nevertheless, these different gelation processes have no influence on the heat release rate. They only influence the water release rate, which is different according to the system studied, thus leading to a short-to-long TTI value. The water release rate is slower for hydrogel A (which is a ionically cross-linked hydrogel) than for hydrogel $\mathrm{C}$ and hydrogel $\mathrm{B}$. It is assumed that the water released rate from a hydrogel depends on the degree of chemical bonding of 
water with the network and the ease to break these bonds (which is easily in the case of hydrogel B and C compared to hydrogel A) [43], [44].

When VMT is added in the hydrogel, a completely different behavior is observed: a very low HRR is measured for samples containing hydrogel B+VMT and C+VMT compared to samples with hydrogel $\mathrm{A}+\mathrm{VMT}$. The VMT organization and its link with thermal insulating mechanism was investigated using different techniques namely confocal microscope, EPMA and XRD analysis. It is noteworthy that under temperature VMT particles organize themselves and form a network which act as a physical barrier to delay the heat propagation. The efficiency of the physical barrier formed depends on i) the initial VMT distribution in hydrogel phase, and ii) the VMT organization and orientation during the heat exposure. On the one hand, the initial VMT distribution in hydrogel phase is a significant factor to provide an efficient thermal barrier because it influences the formation of VMT network upon heating. On the other hand, the VMT network formed during fire testing is very important. The tighter and more organized VMT network is, the less gas can be released to feed to the flame (as it was previously described with EPMA observations). For hydrogel B (Figure 15 a) and hydrogel C (Figure 15 c) VMT particles have an anisotropic distribution, with preferential orientation (confocal microscopy observations - see Figure 3). When these samples are exposed to heat, the water contained in the hydrogel phase boils and the VMT particles migrate through to the top section. Due to their initial anisotropic distribution the VMT particles rapidly form an efficient physical barrier of high tortuosity constituted by aligned and stacked VMT platelets, which limits the gas emission, causing fast extinguishment. Therefore, a very low THR and pHRR are measured, due to this physical barrier. At the end of the fire test, the initial design is retained, which explains the efficient fire protective performances.

In comparison, VMT particles in hydrogel A+VMT (Figure $16 \mathrm{~b}$ ) have an isotropic distribution. When 3D-H A+VMT is exposed to heat, the water contained in the hydrogel boils, and all the VMT particles migrate towards the surface without preferential orientation. The VMT particles organize in clusters, surrounded by polymer (EPMA observations - see figure 7). The physical barrier formed in that case if not gas proof. Voids are observed between the VMT particles, allowing gases to circulate, and thus feeding the flame. Therefore, a high rate of heat release is measured. At the end, only some parts of the design are retained.

Finally, depending on the fast (for systems with hydrogel B+VMT and C+VMT) or slow (for system with hydrogel A+VMT) flame extinguishment, the crystalline structure of the VMT network is modified (XRD analysis). For the systems with hydrogel B+VMT or hydrogel C+VMT, a fast flame extinguishment is observed. The high temperature exposure time is thus less important compared to that reached for the system with hydrogel A+VMT. As a consequence, for system with hydrogel B+VMT and $\mathrm{C}+\mathrm{VMT}$, a crystalline transition similar to that obtained for $\mathrm{VMT}$ at $100^{\circ} \mathrm{C}$ is observed. It highlights a higher interlayer stacking distance. In comparison, Clusters of VMT located on surface are submitted to a high temperature due to the flame. As a consequence, the system with hydrogel A+VMT have a 
crystalline transition similar to that obtained for VMT at $800^{\circ} \mathrm{C}$ (XRD analysis - see figure 11), which means the interlayer stacking distance is lower [39], [40]. XRD analysis thus highlight that no chemical interactions occur between the VMT particles and the polymer, and that different hydration levels and interlayer stacking distance between VMT particles are observed between the hydrogels. These analyses confirm that VMT has only a physical action.
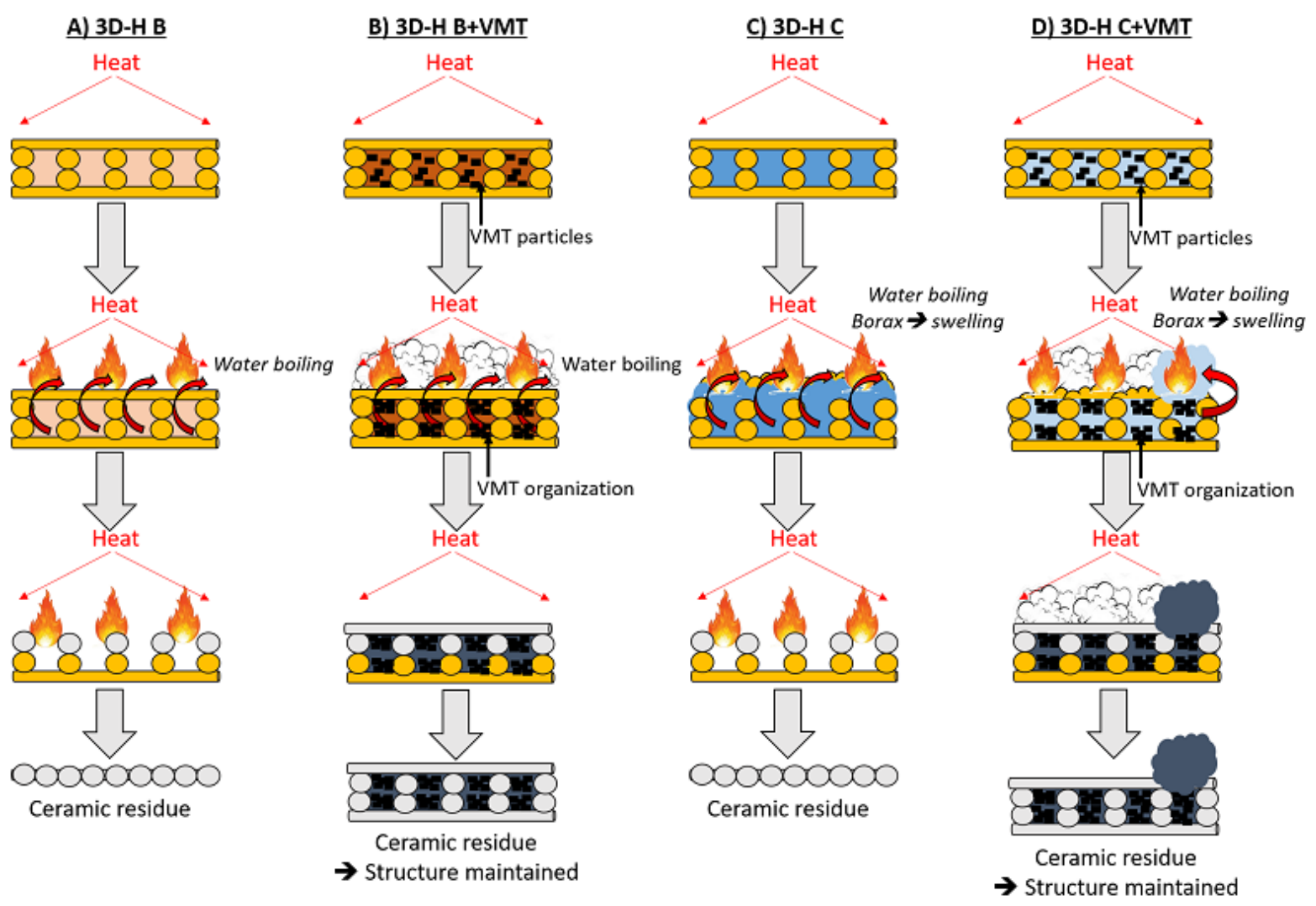

Figure 15. Illustration of fire behavior mechanism of new hydrogel sandwich multi-materials (a) $3 D-H B, b) 3 D-H B+V M T$, c) $3 D-H C, d) 3 D-H C+V M T)$.

When VMT particles are isotropically distributed, as it is the case in hydrogel A+VMT, the physical barrier is not as efficient as previously, and thus no significant improvement is measured in terms of THR and pHRR. To improve that, $\mathrm{K}_{2} \mathrm{CO}_{3}$ was incorporated in this system. Efficient fire protection performances are measured for $3 \mathrm{D}-\mathrm{H} \mathrm{A}+\mathrm{VMT}+\mathrm{K}_{2} \mathrm{CO}_{3}$, with a very low THR and pHRR during MLCC tests. These low values can be explained by the combination of two phenomena, as illustrated in Figure $16 \mathrm{c}$. On one hand, $\mathrm{K}_{2} \mathrm{CO}_{3}$ acts in gas and condensed phase [13]. When the sample is exposed under a radiative heat flux, the water contained in the hydrogel starts to boil and vaporizes into the flame (as confirmed by the purple flame coloration). Therefore, the solution of $\mathrm{K}_{2} \mathrm{CO}_{3}$ is dissociated. With the high flame temperature, the decarbonation of $\mathrm{KHCO}_{3}$ occurs and produces two nonflammable gases $\left(\mathrm{CO}_{2}\right.$ and $\left.\mathrm{H}_{2} \mathrm{O}\right)$, provoking a fast flame extinguishment. This dramatically reduces the heat release rate and consequently improves the fire protective performance of the material. In parallel, the $\mathrm{K}_{2} \mathrm{CO}_{3}$ 
formed reacts with the ATH contained in the polymer matrix, which leads to the formation of another ceramic composed of $\mathrm{Al}$ and $\mathrm{K}$ (as demonstrated using XRD analysis). On the other hand, a physical action occurs with VMT particles contained in the hydrogel. Under heat exposure, the VMT particles have a preferential orientation around the polymer wall, allowing to retain the initial design. With these two phenomena, significant fireproof properties are achieved.

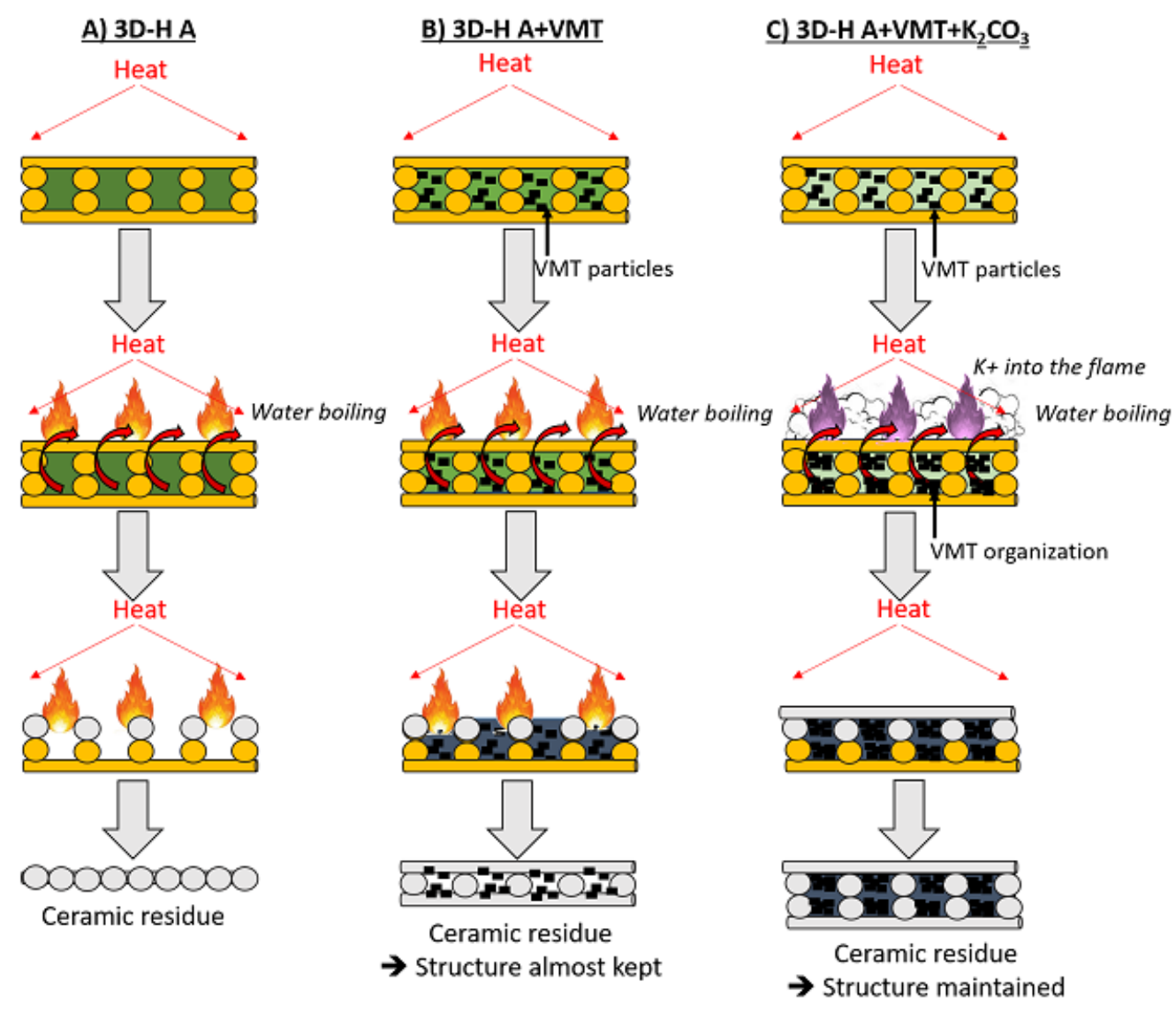

Figure 16. Illustration of fire behavior mechanism of new hydrogel sandwich multi-materials (a) $3 D-H A, b) 3 D-H A+V M T$, c) $\left.3 \mathrm{D}-\mathrm{H} \mathrm{A}+\mathrm{VMT}+\mathrm{K}_{2} \mathrm{CO}_{3}\right)$.

\section{Conclusions}

A new concept of sandwich multi-material, combining polymer 3D printing design and hydrogel filling was elaborated. The design developed, composed of two shells completely filled in with $100 \%$ polymer, and a core with $30 \%$ of polymer inside, was retained. However, the empty cells created by the design were not filled with a standard liquid or solid phase, but with a hydrogel phase to simplify the process and find a solution to sealing issues provoked by the porosity of the material. Three waterborne hydrogels, with various gelation processes were thus elaborated. Vermiculite was incorporated to improve their fire protective performances. It was revealed that hydrogels improve the TTI of systems, 
and that VMT can in certain cases (e.g. for hydrogel B and C) dramatically reduce the heat release rate during heat exposure. These results were correlated with EPMA measurements and XRD analyses, which highlight the influence of VMT particles orientation and organization under temperature, and their influence on crystalline structure. To try to improve fire performances, $\mathrm{K}_{2} \mathrm{CO}_{3}$ was incorporated in the hydrogel phase. When $\mathrm{K}_{2} \mathrm{CO}_{3}$ is dissociated in water, it acts in gas (by diluting flame with $\mathrm{CO}_{2}$ and $\mathrm{H}_{2} \mathrm{O}$ released) and condensed phases (by forming a thermal protective ceramic residue). Therefore, by combining $\mathrm{K}_{2} \mathrm{CO}_{3}$ and VMT in a $3 \mathrm{D}$ printed system, a design with excellent fireproof performances is conceived.

The interest of using hydrogel as structural constituents of multimaterials to design fire retardant systems was thus established. It can be envisioned for example to use this type of materials for structural elements in buildings, such as floor or wall covers. However, a hydrogel will dry out after a certain period of time, losing its flame retardant properties. Therefore, the durability of hydrogel-containing materials is an important point to be addressed in further studies, by using hygroscopic species, or by designing some kind of barrier to prevent the water from evaporating. Another idea could be to use a silicon polymer to act as a water barrier.

\section{Acknowledgement}

We would thank the SEM facility in Lille (France) which is supported by the conseil Régional du NordPas de Calais, and the European Regional Development Fund (ERDF).

Chevreul Institute (FR 2638), Ministère de l'Enseignement Supérieur et de le Recherche, Région Hauts de France, and FEDER are acknowledged for supporting and funding XRD facilities. We would in particular acknowledge Pascal Roussel for his help and advice regarding XRD analysis.

We thank the UMS2014/US41 PLBS- BICeL Campus CS Facility for access to instruments.

\section{Authors contribution}

S.B., M.J. and F.S. supervised the work and contributed to the paper writing. Se.B. carried out all EPMA and SEM observations, with L.G. and A-L.D.. E.R. did confocal microscopy observations with L.G. and A-L.D.. F.B. helped for XRD analysis with L.G. and A-L.D.. L.G. and A-L.D. also discussed, and analyzed all results together. A-L.D. wrote the introduction and abstract part. L.G. carried out all MLCC tests and samples elaboration. She also finalized the results, figures and wrote the paper.

\section{Funding}

This work has received funding from the European Research Council (ERC) under the European Union's H2020- the framework programme for Research and Innovation (2014-2020) ERC Grant Advances Agreement N ${ }^{\circ} 670747-E R C 2014$ AdG/FireBar-Concept for FireBar Concept project. 


\section{Conflicts of interest}

The authors declare no conflict of interest. The funders had no role in the design of the study; in the collection, analyses, or interpretation of data; in the writing of the manuscript, and in the decision to publish the results.

\section{References}

[1] T. D. Ngo, A. Kashani, G. Imbalzano, K. T. Q. Nguyen, and D. Hui, "Additive manufacturing (3D printing): A review of materials, methods, applications and challenges," Compos. Part B Eng., vol. 143, no. December 2017, pp. 172-196, 2018.

[2] H. Wu et al., "Recent Developments in Polymers/Polymer Nanocomposites for Additive Manufacturing,” Prog. Mater. Sci., vol. 111, no. April 2019, p. 100638, 2020.

[3] Y. Guo et al., "Engineering flame retardant biodegradable polymer nanocomposites and their application in 3D printing," Polym. Degrad. Stab., vol. 137, pp. 205-215, 2017.

[4] $\mathrm{H}$. Wu et al., "Additive manufacturing of flame-retardant polyamide 6 nanocomposites via Fused Filament Fabrication (FFF)," in International SAMPE Technical Conference, 2019.

[5] W. P. Fahy and J. H. Koo, "Advancement in the study of 3D printable flame retardant polyamide 11 nanocomposites," in International SAMPE Technical Conference, 2019.

[6] H. Wu, M. Sulkis, J. Driver, A. Saade-Castillo, A. Thompson, and J. H. Koo, "Multi-functional ULTEM $^{\mathrm{TM}} 1010$ composite filaments for additive manufacturing using Fused Filament Fabrication (FFF)," Addit. Manuf., vol. 24, no. August, pp. 298-306, 2018.

[7] L. Geoffroy, F. Samyn, M. Jimenez, and S. Bourbigot, "Additive manufacturing of fire-retardant ethylene-vinyl acetate," Polym. Adv. Technol., vol. 30, no. 7, pp. 1878-1890, 2019.

[8] Z. Tianwei, L. Hao, H. Zhiyue, D. Zhiming, and W. Yong, "Active substances study in fire extinguishing by water mist with potassium salt additives based on thermoanalysis and thermodynamics," Appl. Therm. Eng., vol. 122, pp. 429-438, 2017.

[9] J. D. Birchah, "On the Mechanism of Flame Inhibition by Alkali Metal Salts," Combust. Flame, vol. 14, pp. 85-96, 1970.

[10] C. T. Ewing, F. R. Faith, J. T. Hughes, and H. W. Carhart, "Flame Extinguishment Properties of Dry Chemicals : Extinction Concentrations for Small Diffusion Pan Fires," Fire Technol., no. May, pp. 134-149, 1989. 
[11] V. I. Babushok, G. T. Linteris, P. Hoorelbeke, D. Roosendans, and K. van Wingerden, "Flame Inhibition by Potassium-Containing Compounds," Combust. Sci. Technol., vol. 189, no. 12, pp. 2039 2055, Dec. 2017.

[12] D. Grossman, "Samsung's 'Firevase' Is a Smashing Fire Extinguisher", Popular mechanics, 2019 , available

[Online]

https://www.popularmechanics.com/technology/infrastructure/a26974315/samsungs-firevasethrowable-fire-extinguisher/, consulted on 05/04/2020

[13] L. Geoffroy, F. Samyn, M. Jimenez, and S. Bourbigot, "Innovative 3D printed design to conceive highly fire-retardant multi-material,” Polym. Degrad. Stab., vol. 169, p. 108992, 2019.

[14] W. Cheng, X. Hu, J. Xie, and Y. Zhao, “An intelligent gel designed to control the spontaneous combustion of coal: Fire prevention and extinguishing properties," Fuel, vol. 210, no. April, pp. 826835, 2017.

[15] X. Ren et al., "Novel sodium silicate/polymer composite gels for the prevention of spontaneous combustion of coal," J. Hazard. Mater., vol. 371, no. March, pp. 643-654, 2019.

[16] W. R. K. Illeperuma, P. Rothemund, Z. Suo, and J. J. Vlassak, "Fire-Resistant Hydrogel-Fabric Laminates: A Simple Concept That May Save Lives," ACS Appl. Mater. Interfaces, vol. 8, no. 3, pp. 2071-2077, 2016.

[17] X. F. Cui et al., "Water-retaining, though and self-healing hydrogels and their uses as fireresistant materials," Polym. Chem., vol. 10, pp. 5151-5158, 2019.

[18] L. Hsiao, L. Jing, K. Li, H. Yang, Y. Li, and P. Chen, "Carbon nanotube-integrated conductive hydrogels as multifunctional robotic skin," Carbon N. Y., vol. 161, pp. 784-793, 2020.

[19] Q. Ren, Y. Zhang, J. Li, and J. C. Li, "Synergistic Effect of Vermiculite on the Intumescent Flame Retardance of Polypropylene,” J. Appl. Polym. Sci., vol. 120, no. 2, pp. 1225-1233, 2010.

[20] R. B. L. Hanken et al., "Effect of natural and expanded vermiculite clays on the properties of eco-friendly biopolyethylene-vermiculite clay biocomposites," Compos. Part B Eng., vol. 175, no. December 2018, 2019.

[21] A. A. Cain, M. G. B. Plummer, S. E. Murray, L. Bolling, O. Regev, and J. C. Grunlan, "Ironcontaining, high aspect ratio clay as nanoarmor that imparts substantial thermal/flame protection to polyurethane with a single electrostatically-deposited bilayer," J. Mater. Chem. A, vol. 2, no. 41, pp. 17609-17617, 2014.

[22] S. Lazar, F. Carosio, A. L. Davesne, M. Jimenez, S. Bourbigot, and J. Grunlan, "Extreme Heat Shielding of Clay/Chitosan Nanobrick Wall on Flexible Foam," ACS Appl. Mater. Interfaces, vol. 10, no. 37, pp. 31686-31696, 2018. 
[23] Arkema Functional Polyolefins, "Evatane 28-05: Ethylene-Vinyl Acetate (VA) copolymer with high VA content," 2014.

[24] C. Hoffendahl, G. Fontaine, S. Duquesne, F. Taschner, M. Mezger, and S. Bourbigot, "The fire retardant mechanism of ethylene vinyl acetate elastomer (EVM) containing aluminium trihydroxide and melamine phosphate," RSC Adv., vol. 4, no. 39, pp. 20185-20199, 2014.

[25] Sigma-aldrich, "Product Specification: Sodium alginate," 2015.

[26] Poly(vinyl alcohol), Sigma-aldrich, available [Online] https://www.sigmaaldrich.com/catalog/product/sial/81384?lang=fr\&region=FR\&cm_sp=Insite-_recent_fixed-_-recent5-1, consulted on 05/04/2020

[27] "What is agar-agar", Agargel, available [Online], https://agargel.com.br/en/agar-agar/, consulted on $05 / 04 / 2020$

[28] M. M. Perez-Madrigal, J. Torras, J. Casanovas, M. Häring, C. Aleman, and D. D. Diaz, "Paradigm Shift for Preparing Versatile M 2+ -Free Gels from Unmodified Sodium Alginate," Biomacromolecules, vol. 18, pp. 2967-2979, 2017.

[29] C. Riedo, F. Caldera, T. Poli, and O. Chiantore, "Poly(vinylalcohol)-borate hydrogels with improved features for the cleaning of cultural heritage surfaces," Herit. Sci., vol. 3, no. 23, pp. 1-11, 2015.

[30] C. Karakasyan et al., "Cold gelation of alginates induced by monovalent cations," Biomacromolecules, vol. 11, no. 11, pp. 2966-2975, 2010.

[31] B. Schartel and T. R. Hull, "Development of fire-retarded materials - Interpretation of cone calorimeter data," no. May, pp. 327-354, 2007.

[32] M. M. Martin and L. Lindqvist, "The pH dependence of fluorescein fluorescence," J. Lumin., vol. 10, pp. 381-390, 1975.

[33] E. K. Lavrent, S. G. Starodubtsev, A. R. Khokhlov, V. V Volkov, and K. A. Dembo, "Effect of Polymer Nature on the Structure and Properties of Gel Composites with Incorporated Bentonite Particles," Colloid J., vol. 70, no. 5, pp. 604-608, 2008.

[34] S. G. Starodoubtsev, E. K. Lavrentyeva, A. R. Khokhlov, G. Allegra, A. Famulari, and S. V Meille, "Mechanism of Smectic Arrangement of Montmorillonite and Bentonite Clay Platelets Incorporated in Gels of Poly (Acrylamide) Induced by the Interaction with Cationic Surfactants," Langmuir, vol. 22, pp. 369-374, 2006.

[35] P. Porion, M. Al Mukhtar, S. Meyer, A. M. Fauge, and J. R. C. Van Der Maarel, "Nematic Ordering of Suspensions of Charged Anisotropic Colloids Detected by 23Na Nuclear Magnetic Resonance," J. Phys. Chem. B, vol. 105, pp. 10505-10514, 2001. 
[36] G. Schmidt, A. I. Nakatani, P. D. Butler, and C. C. Han, "Small-Angle Neutron Scattering from Viscoelastic Polymer - Clay Solutions," Macromolecules, vol. 35, pp. 4725-4732, 2002.

[37] M. Huang, Y. Hou, Y. Li, D. Wang, and L. Zhang, "High performances of dual network PVA hydrogel modified by PVP using borax as the structure- forming accelerator," Des. Monomers Polym., vol. 20, no. 1, pp. 505-513, 2017.

[38] K. Haraguchi, K. Murata, and Y. Kimura, "Uniaxial and plane orientations of clay platelets in nanocomposite gels with different compositions during stretching and recovery," Polymer (Guildf)., vol. 116, pp. 439-446, 2017.

[39] G. W. Brindley, "Part III - Methods of Identifying Clays and the Interpretation of Results," in Calys and Clay Minerals, 1952, pp. 119-129.

[40] C. Marcos, Y. C. Arango, and I. Rodriguez, "X-ray diffraction studies of the thermal behaviour of commercial vermiculites," Appl. Clay Sci., vol. 42, no. 3-4, pp. 368-378, 2009.

[41] C. Marcos, Y. C. Arango, and I. Rodriguez, "X-ray diffraction studies of the thermal behaviour of commercial vermiculites," Appl. Clay Sci., vol. 42, no. 3-4, pp. 368-378, 2009.

[42] X. Gong, Z. Guo, and Z. Wang, "Variation of Char Structure during Anthracite Pyrolysis Catalyzed by Fe $2 \mathrm{O} 3$ and Its Influence on Char Combustion Reactivity," Energy Fuels, vol. 36, no. 10, pp. 1-6, 2009.

[43] B. Bellich, M. Borgogna, M. Cok, and A. Cesaro, "Release Properties of Hydrogels : Water Evaporation from Alginate Gel Beads,” Food Biophys., vol. 6, no. June, pp. 259-266, 2011.

[44] D. R. Rohindra, A. V Nand, and J. R. Khurma, "Swelling properties of chitosan hydrogels," South Pacific J. Nat. Sci., vol. 22, pp. 32-35, 2004. 


\section{Appendix}

Table A1. Fire protection performances values of each system studied

\begin{tabular}{cccc}
\hline Polymer matrix & TTI (s) & THR (MJ/m²) & pHRR (kW/m²) \\
\hline 3D-air & $26 \pm 1$ & $49.4 \pm 0.3$ & $225 \pm 13$ \\
\hline 3D-K2 OO$_{3 \text { sat.-liquid }}$ & $34 \pm 6(\times 1.3)$ & $18 \pm 1(-63 \%)$ & $52 \pm 4(-77 \%)$ \\
\hline 3D-H A & $168 \pm 6(\times 6.5)$ & $57 \pm 2(16 \%)$ & $253 \pm 5(-12 \%)$ \\
\hline 3D-H A+VMT & $196 \pm 2(\times 7.5)$ & $46 \pm 1(-2 \%)$ & $203 \pm 7(-15 \%)$ \\
\hline 3D-H A +VMT+K2CO & $50 \pm 6(\times 1.9)$ & $5.65 \pm 0.09(-88 \%)$ & $32 \pm 1(-86 \%)$ \\
\hline 3D-H B & $74 \pm 6(\times 2.8)$ & $63 \pm 4(28 \%)$ & $226 \pm 6(0.4 \%)$ \\
\hline 3D-H B+VMT & $31 \pm 2(\times 1.2)$ & $7.1 \pm 0.3(-86 \%)$ & $81 \pm 3(-64 \%)$ \\
\hline 3D-H C & $26.5 \pm 0.7(\times 1)$ & $48 \pm 5(-2 \%)$ & $219 \pm 4(-3 \%)$ \\
\hline 3D-H C+VMT & $38 \pm 6(\times 1.5)$ & $9.5 \pm 0.2(-82 \%)$ & $144 \pm 5(-36 \%)$ \\
\hline
\end{tabular}

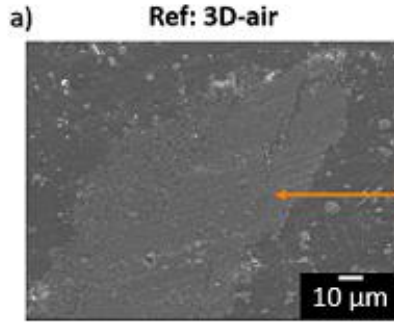

b)
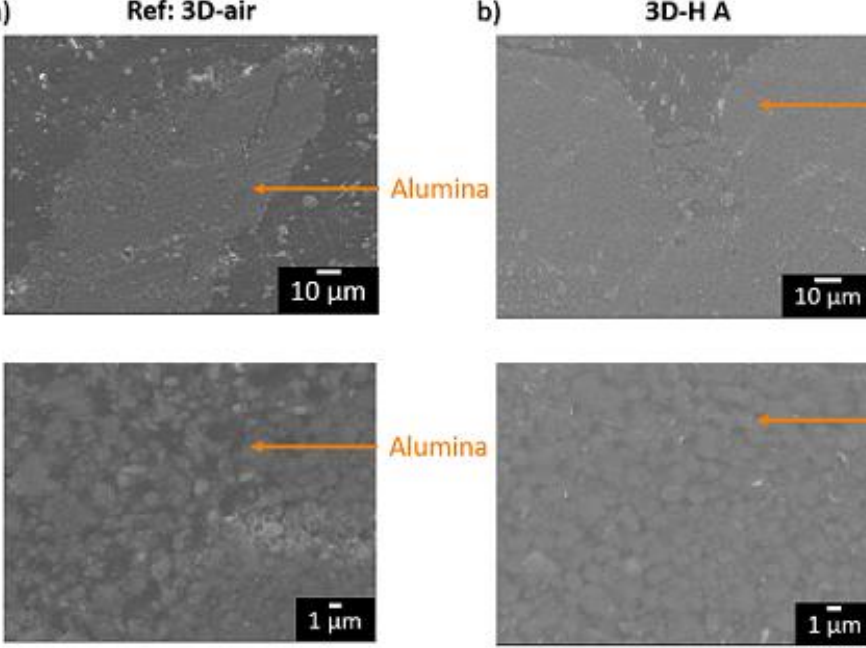
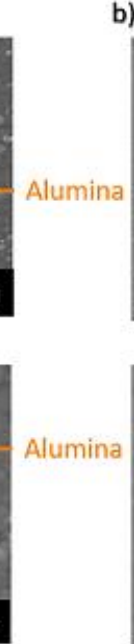

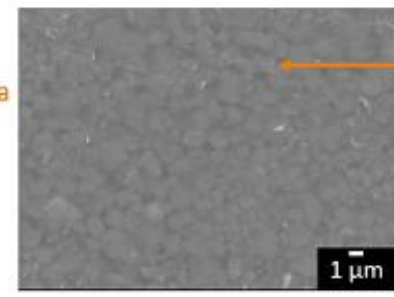

c)

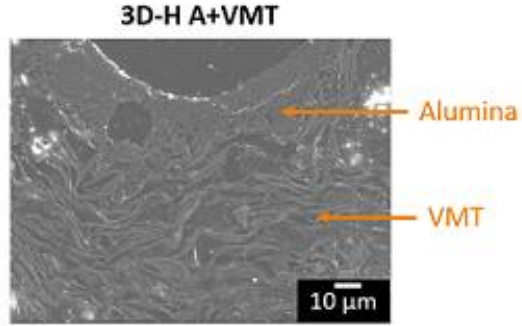

$10 \overline{\mu m}$

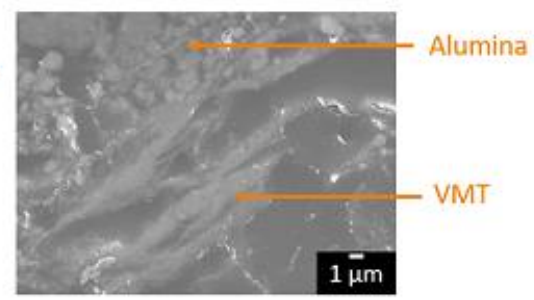

Figure A1. Cross-section of (a) 3D-air, b) 3D-H A and c) 3D-H A+VMT), using SEM observation.
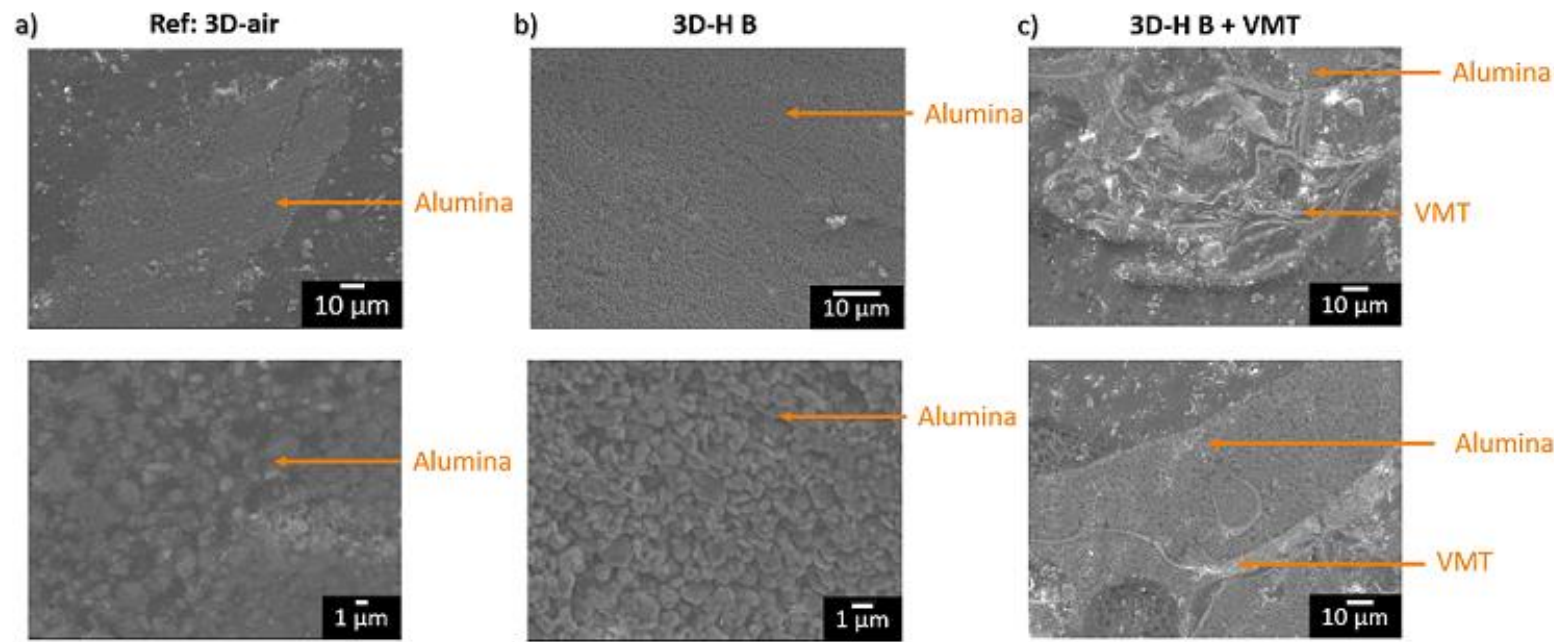

Alumina

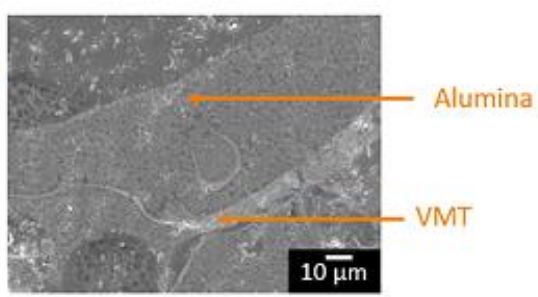


Figure A2. Cross-section of (a) 3D-air, b) 3D-H B and c) 3D-H B+VMT), using SEM observation.

a)
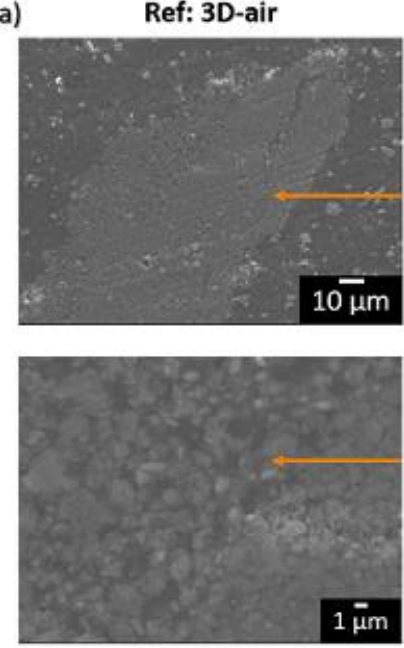

b)

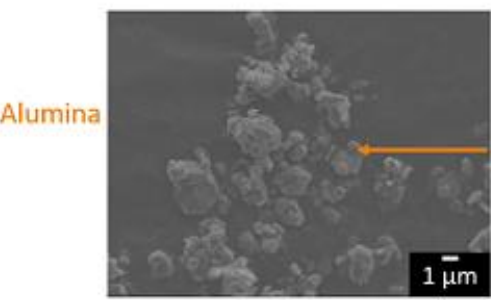

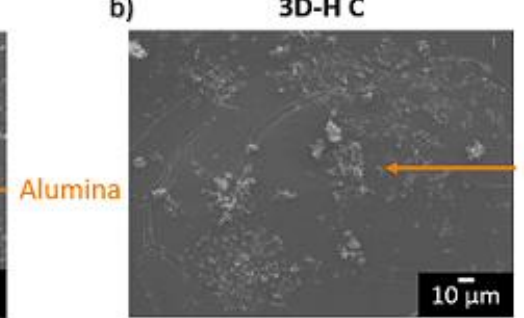

3D-H C+VMT
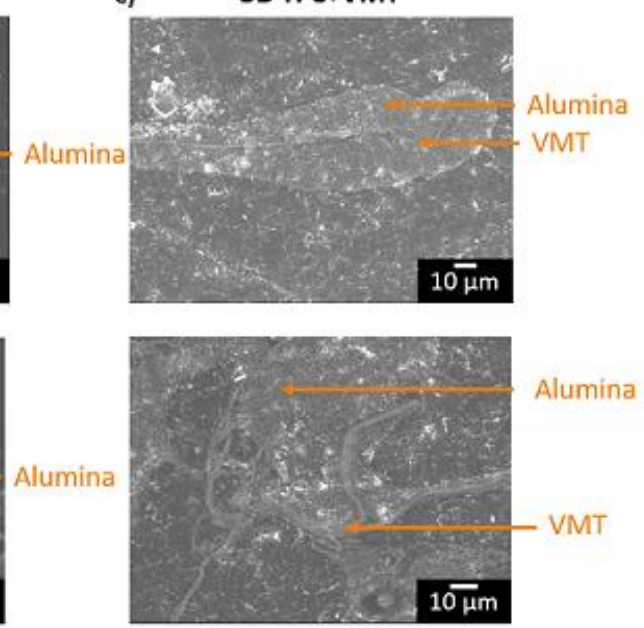

Figure A3. Cross-section of (a) 3D-air, b) 3D-H C and c) 3D-H C+VMT), using SEM observation.
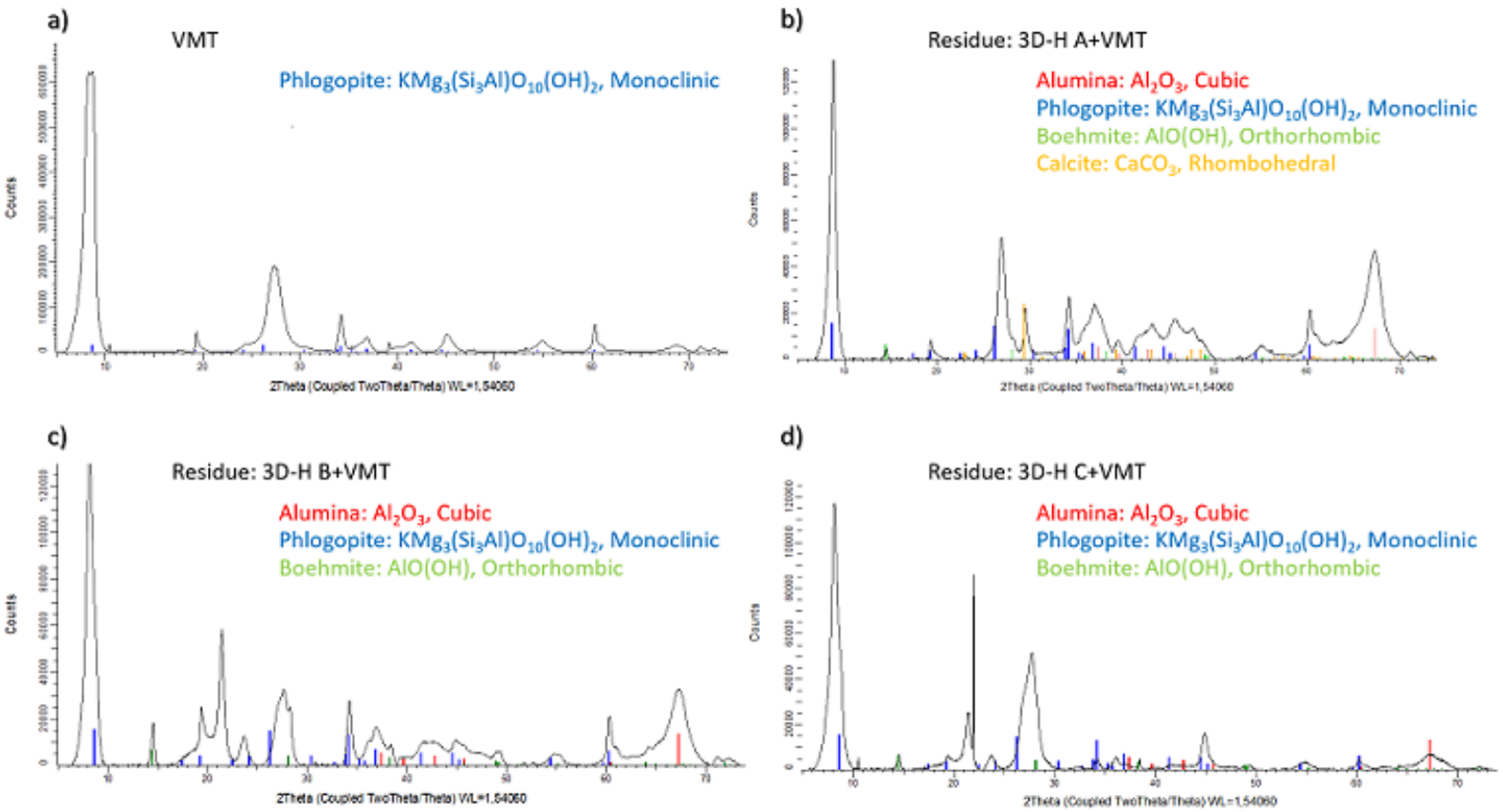

Figure A4. XRD of (a) VMT, b) residue 3D-HA+VMT, c) residue 3D-H B+VMT, d) residue 3D-H C+VMT). 


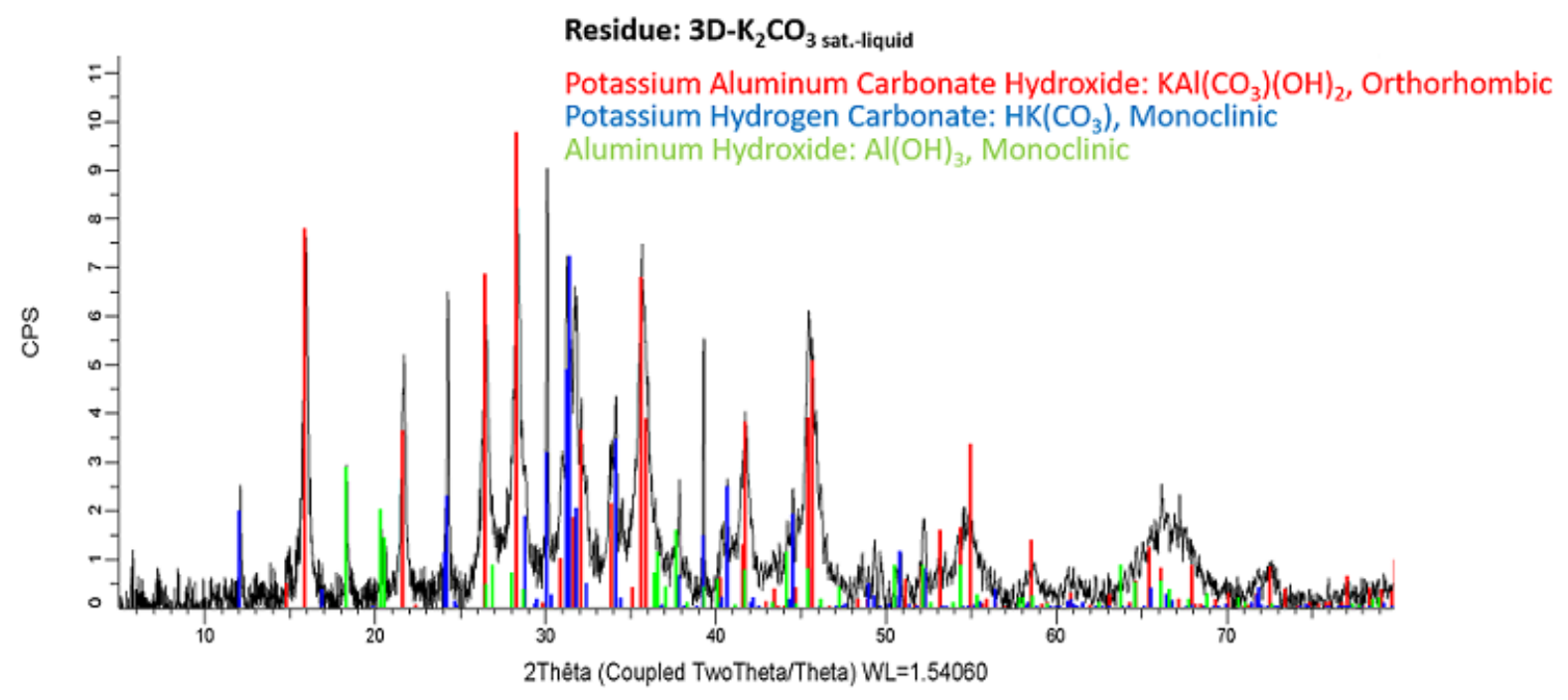

Figure A5. XRD of residue $3 \mathrm{D}-\mathrm{K}_{2} \mathrm{CO}_{3}$ sat-liquid.

a)
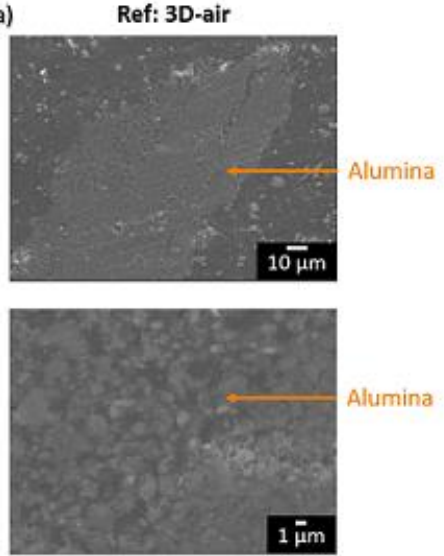

b)

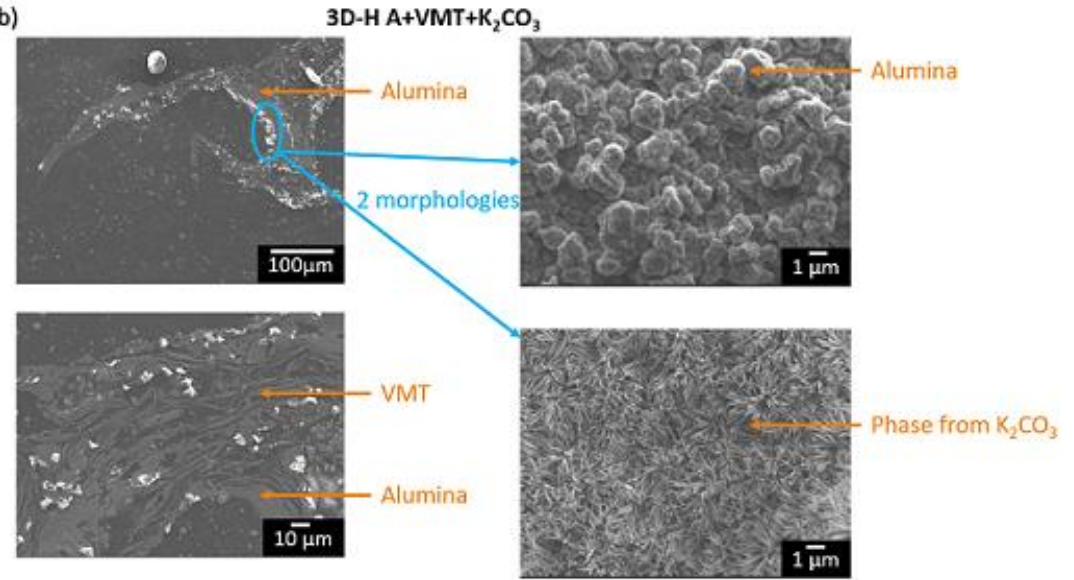

Figure A6. Cross-section of (a) 3D-air, b) 3D-H A+VMT+K $\mathrm{C}_{2} \mathrm{CO}_{3}$ ), using SEM observation. 